\title{
Current Status and Future Challenges of Sleep Monitoring Systems: Systematic Review
}

Qiang Pan ${ }^{*}, \mathrm{MSc}$; Damien Brulin ${ }^{*}, \mathrm{PhD}$; Eric Campo*, $\mathrm{PhD}$

LAAS-CNRS, University of Toulouse, Toulouse, France

*all authors contributed equally

Corresponding Author:

Eric Campo, PhD

LAAS-CNRS

University of Toulouse

7, avenue du Colonel Roche

Toulouse, 31400

France

Phone: 33561337961

Email: eric.campo@univ-tlse2.fr

\section{Abstract}

Background: Sleep is essential for human health. Considerable effort has been put into academic and industrial research and in the development of wireless body area networks for sleep monitoring in terms of nonintrusiveness, portability, and autonomy. With the help of rapid advances in smart sensing and communication technologies, various sleep monitoring systems (hereafter, sleep monitoring systems) have been developed with advantages such as being low cost, accessible, discreet, contactless, unmanned, and suitable for long-term monitoring.

Objective: This paper aims to review current research in sleep monitoring to serve as a reference for researchers and to provide insights for future work. Specific selection criteria were chosen to include articles in which sleep monitoring systems or devices are covered.

Methods: This review investigates the use of various common sensors in the hardware implementation of current sleep monitoring systems as well as the types of parameters collected, their position in the body, the possible description of sleep phases, and the advantages and drawbacks. In addition, the data processing algorithms and software used in different studies on sleep monitoring systems and their results are presented. This review was not only limited to the study of laboratory research but also investigated the various popular commercial products available for sleep monitoring, presenting their characteristics, advantages, and disadvantages. In particular, we categorized existing research on sleep monitoring systems based on how the sensor is used, including the number and type of sensors, and the preferred position in the body. In addition to focusing on a specific system, issues concerning sleep monitoring systems such as privacy, economic, and social impact are also included. Finally, we presented an original sleep monitoring system solution developed in our laboratory.

Results: By retrieving a large number of articles and abstracts, we found that hotspot techniques such as big data, machine learning, artificial intelligence, and data mining have not been widely applied to the sleep monitoring research area. Accelerometers are the most commonly used sensor in sleep monitoring systems. Most commercial sleep monitoring products cannot provide performance evaluation based on gold standard polysomnography.

Conclusions: Combining hotspot techniques such as big data, machine learning, artificial intelligence, and data mining with sleep monitoring may be a promising research approach and will attract more researchers in the future. Balancing user acceptance and monitoring performance is the biggest challenge in sleep monitoring system research.

(JMIR Biomed Eng 2020;5(1):e20921) doi: 10.2196/20921

\section{KEYWORDS}

EEG; ECG; classification; mobile phone 


\section{Introduction}

\section{Background}

Sleep is crucial for human health and quality of life. Poor sleep and sleep disorders have been increasingly prevalent among the world's older population [1,2]. Polysomnography (PSG) has long been the gold standard to quantify sleep time, to differentiate sleep stages, and to assess sleep fragmentation. PSG provides comprehensive physiological information during sleep including electroencephalograms (EEGs), electrocardiograms (ECGs), electromyography (EMG), electrooculography (EOG), oral-nasal airflow, body position, thoracic and abdominal movements, pulse oximetry, and limb movements. The serious impact of sleep on health and well-being is the dominant motivation for sleep monitoring.

- On personal health, sleep is a foundation for good health as important as diet and exercise, according to the National Sleep Foundation. Poor sleep can lead to adverse health consequences, including obesity [3], cardiovascular disease [4], and depressive disorders [5]. Sleep is also associated with creativity [6], memory consolidation [7], and cognitive function [8]. Patients affected by sudden cardiac death with sleep disorders such as obstructive sleep apnea (OSA) have been reported to have peak mortality during sleep hours [9].

- On society, the incidence of sleep disorders appears to be a concern worldwide. Among the global population, $16.6 \%$ of people in Africa and Asia [10], 18\% of people in Europe [11], and more than $20 \%$ of people in North America $[12,13]$ are affected by nocturnal sleep disorders. Such prevalence has led to a range of societal problems, such as high rates of chronic diseases, road traffic accidents, and workplace accidents. Approximately $13 \%$ of work injuries are due to sleep problems [14]. In the United States, the expenditure for the treatment of moderate-to-severe sleep disorders and related disorders amounts to US \$165 billion per year, far more than the costs of treating diseases such as heart failure, stroke, hypertension, and asthma, which range from US \$20 to US $\$ 80$ per year [15]. In 5 OECD (Organisation for Economic Co-operation and Development) countries, the economic costs of sleep deprivation are $1.35 \%$ (Canada), $1.56 \%$ (Germany), $1.88 \%$ (United Kingdom), 2.28\% (United States), and 2.92\% (Japan) of their respective gross domestic product (GDP) [16].

\section{Sleep Stages Scoring Rules}

Clinicians can obtain reliable sleep monitoring results, such as sleep stages, by analyzing the PSG recording during the night. For sleep stage guidelines and scoring rules, the R\&K rules proposed by Rechtschaffen and Kales in 1968 [17] were used until 2007, when the American Academy of Sleep Medicine (AASM) updated the scoring manual commonly referred to as the AASM scoring manual [18]. The R\&K rules and the AASM rules differ in the terminology used. The $\mathrm{R} \& \mathrm{~K}$ rules divide sleep into 6 distinct stages: W (wake); non-rapid eye movement (non-REM [NREM]) stages S1, S2, S3, and S4; and REM sleep stage. The AASM rules recognize 5 sleep stages: W (wake) stage N1 (formerly stage 1 sleep), stage N2 (formerly stage 2 sleep), stage N3 (formerly stages 3 and 4 sleep), and stage $\mathrm{R}$ sleep (formerly stage REM sleep), as illustrated in Figure 1.

For the same sleep, the scoring results obtained from $R \& K$ rules and the AASM rules will be slightly different. One study [19] adopted both rules to score PSG sleep recordings of healthy subjects and patients (38 women and 34 men) aged 21 to 86 years. The results showed that sleep latency, REM latency, total sleep time, and sleep efficiency were not affected by the classification standard. In contrast, the time (in minutes and as a percentage of total sleep time) spent in stage 1 (S1/N1), stage 2 (S2/N2), and slow wave sleep (S3+S4/N3) differed significantly between the R\&K and AASM classifications. Although light and deep sleep increased (S1 vs N1 [+10.6 min, $(+2.8 \%)]: P<.01 ; \mathrm{S} 3+\mathrm{S} 4$ vs N3 [+9.1 $\min (+2.4 \%)]: P<.01)$, stage 2 sleep decreased significantly according to the AASM rules (S2 vs N2 [-20.5 $\mathrm{min},(-4.9 \%)]: P<.01)$.

The differences between the results of the 2 sleep standards can be attributed to the different rules used [20].

The reader is reminded that sleep stages should not be considered as distinct entities but rather as a gradual transition of a waveform. Sleep usually follows a predictable pattern, moving cyclically between the light sleep stage, the deep sleep stage, and REM. Each sleep cycle typically lasts about $90 \mathrm{~min}$ and is repeated 4 to 6 times during the night. In each sleep cycle, people usually experience a transition from light to deep sleep first and then switch to REM. However, some stages can be skipped during sleep. For example, one can switch to REM or return directly to deep sleep from REM sleep [21]. Sleep quality is analyzed using standard parameters such as sleep efficiency, total sleep time, sleep latency, sleep stages 1 and 2, slow-wave sleep (sleep stages 3 and 4), rapid eye movement sleep, wake time after sleep onset, and nocturnal wake time [22]. 
Figure 1. Terminology used by R\&K and AASM for sleep stages scoring.

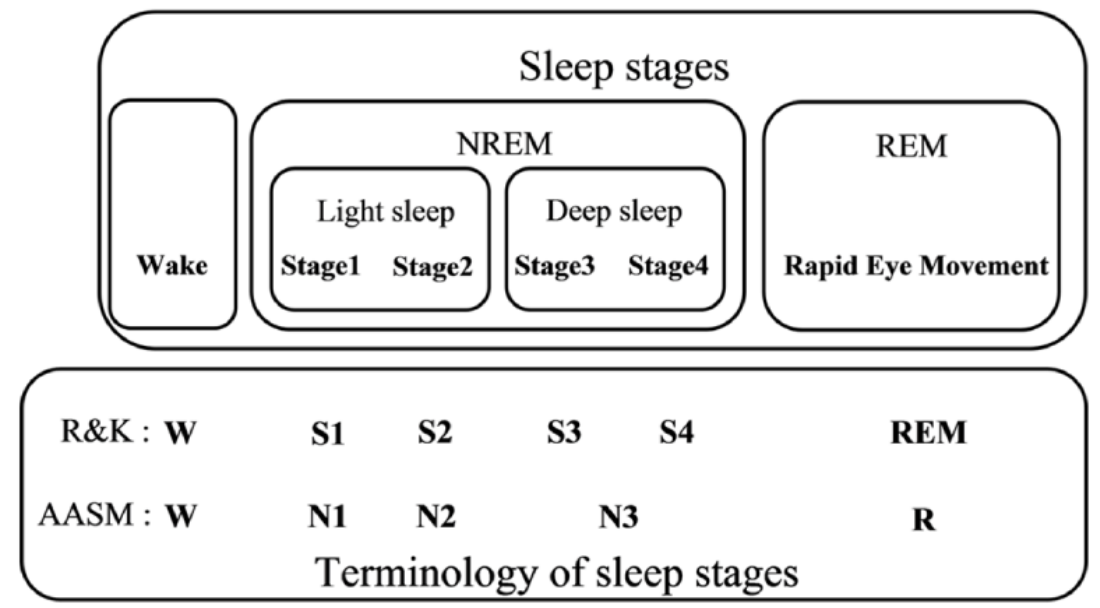

Sleep disorders, the most recently released third edition of the International Classification of Sleep Disorders (ICSD-3) has identified 7 major categories of sleep disorders that include insomnia, sleep-related breathing disorders, central hypersomnolence disorders, circadian rhythm sleep-wakefulness disorders, sleep-related movement disorders, parasomnia, and other sleep disorders [23]. Most sleep disorders can be monitored by sleep monitoring systems, and some of them are detailed below:

- Insomnia refers to impairment in the quality and quantity of sleep. According to Ohayon [24], $10 \%$ to $30 \%$ of the adult population is affected by insomnia. The ICSD-3 criteria for this diagnosis include (1) a report of sleep initiation or maintenance problems, (2) adequate opportunity and circumstances for sleep, and (3) consequences during the day. The ICSD-3 duration criterion for chronic insomnia disorder is 3 months, and a frequency criterion (at least 3 times per week) was added.

- Sleep apnea is characterized by pauses in breathing or instances of shallow breathing during sleep [25]. Due to sleep apnea, the patient wakes up regularly throughout the night to retrieve breathing. Frequent awakening results in very poor quality of sleep and excessive daytime fatigue. Usually, sleep apnea may be accompanied by loud snoring, which can be easily monitored by a microphone (many researchers have studied Snoring signal processing-based methods to achieve a supplementary diagnosis way of sleep apnea) [26-28].

- Restless legs syndrome $(R L S)$ is based on an urge to move the legs, sometimes accompanied by an uncomfortable sensation that (1) occurs primarily with rest or inactivity, (2) is partially or totally relieved by the movement, for as long as the movement occurs, and (3) occurs primarily in the evening or night [29]. Up to $30 \%$ of cases are caused by iron deficiency. These abnormal leg movements can be easily monitored with an accelerometer [30-32].

- Periodic limb movement disorder (PLMD) is characterized by abnormal limb movements and is responsible for deterioration in sleep quality [33]. For young people, it will be considered as pathologic when the index of periodic limb movement during sleep (PLMS; number of PLMS per hour) is greater than 5. For older people, an index of PLMS greater than 15 is usually adopted as the pathological threshold. This disorder can be detected by using EMG [34] or actigraphy [30].

- Disorders of arousal from NREM(DAN) include confusion arousal, sleepwalking, sleep terrors, and sleep-related eating disorders $[23,35]$. The general criteria for disorders of arousal include (1) recurrent episodes of incomplete awakening, (2) absent or inappropriate responsiveness, (3) limited or no cognition or dream report, and (4) partial or complete amnesia for the episode. Detection of repeated wakes during the NREM stage can be a sign of DAN. This disorder can be detected using EEG.

- $\quad$ REM sleep behavior disorder (RBD) is characterized by the intermittent loss of REM sleep atonia and the appearance of elaborate motor activity associated with the situation in dreams, such as repeated episodes of behavior or vocalization arising from REM [36]. When specific movements and sounds are detected during the REM stage, a suspicion of RBD should be considered. This disorder could be detected by using a microphone, actigraphy, and EEG.

Therefore, there appears to be a growing interest in researching new sleep monitoring system solutions to provide rapid, reliable, and long-term monitoring results to users and clinicians. Innovative home-used sleep monitoring systems offer users access to sleep phases and quality by themselves and can be a reference for the diagnosis of sleep disorders by clinicians.

For sleep monitoring, a sleep monitoring system can include a wide range of wearable or noncontact devices, including sensors, actuators, smart fabrics, power supplies, wireless communication networks, processing units, multimedia devices, user interfaces, software, and algorithms for data capture, processing, and decision support. These systems are able to measure vital signs, such as body and limb movements, body and skin temperature, heart rate, ECGs, EEGs, EMG, and respiration rate. The measurements are transmitted via a sensor network either to a central connection node, such as a personal digital assistant, or directly to a medical center for storage, data processing, and decision making.

To discuss this potential, this paper aimed to review the current state of research and development in the field of sleep 
monitoring system, highlighting the main features of the most promising projects being developed and future challenges.

\section{Methods}

\section{Overview}

With the growing appearance of sleep problems, the sleep monitoring system study has been one of the hotspots in the field of smart human monitoring. As a result, advances in sleep monitoring system development technology are continuously accelerating. Simple, lightweight, and small-size sensor systems are being adopted to acquire sleep-related physiological information. These systems are designed to be adaptable to the gold standard PSG, including sleep stages, sleep or wake, sleep apnea, sleep positions, and so on. Furthermore, the advantages of such a system over the traditional PSG method are that it is affordable, requires little or no technician intervention, is installed in the home, and can be used over the long term. The systems have developed rapidly with the progress made in the miniaturization of sensors, the reduction of energy consumption, and various communication possibilities (Bluetooth, Wi-Fi, Sigfox, LoRa, and NB-IoT). These technologies enable current sleep monitoring systems to be less intrusive and effective, with remote and continuous monitoring. In this review, specific selection criteria are chosen as reference articles on sleep monitoring systems.

\section{Inclusion Criteria for Sleep Monitoring System Search}

Most sleep monitoring system research projects have focused on smart, portable, and nonintrusive devices that encompass wireless communication, moving the monitoring site from the hospital to the home, in patch or noncontact form. Systems that have the following features are included:

- Wearable, portable, nonintrusive, wireless, and noncontact. - Patch, body sensor system, and sensor network.

- Band, watch, textile, bedsheet, and belt.

- Mobile, stationary, ambulatory, at home, and remote.

Automatic collection and transmission of acquired data and processing results can help physicians and caregivers easily follow sleep conditions over time. In addition, it can make it easier to find trends in the data, providing insight into individualized sleep patterns.

\section{Search Methods and Strategies}

This literature review focuses on the presentation of the hardware and software adopted in the current sleep monitoring system. We have included journal publications, conference publications, and information on related websites. The keywords for material collection are shown in Textbox 1. We conducted a keyword search in Web of Science, PubMed, and PubMed Central.

Textbox 1. Keywords used for the literature search.

- $\quad$ Sleep

- $\quad$ Sleep quality

- Sleep monitor

- Sleep monitor system

- $\quad$ Sleep monitor and sensor

- Sleep monitor and smart patch

- Sleep monitor and commercial products

- Sleep monitor at home

- Polysomnography

- Electroencephalography

- Rapid eye movement or light or deep sleep or wake

- $\quad$ Long-term sleep monitor

- $\quad$ Sleep phase classification

- Sleep stage classification

- Noncontact sleep monitor

- $\quad$ Nonintrusive sleep monitor

- Noninvasive sleep monitor

- $\quad$ Sleep big data

- $\quad$ Sleep data mining

- $\quad$ Sleep deep learning

- $\quad$ Sleep machine learning

- Sleep artificial intelligence 


\section{Results}

Owing to a large number of articles and abstracts retrieved, it was decided to include only articles published for the period 2013 to 2018 in Web of Science, PubMed, and PubMed Central. By counting the number of hits in the bibliographic database for each keyword, we can find search hotspots in this field and aspects that are still rarely covered. In this first search, we tried to find articles and abstracts, and websites with the keywords listed in Textbox 1. Keywords are used alone or combined using and, or operators. The article should report a clear description of the systems, the recipients or users requiring these systems, and issues related to sleep monitoring systems, including the parameters measured, wireless sensor network (WSN), user needs, and user acceptance. As this review does not constitute an exhaustive presentation of the scientific literature in the field of sleep monitoring systems, only a few representative sleep monitoring system research and development projects or products from academia or industry are presented.

The number of hits in the sleep monitoring system research field between 2013 and 2018 is shown in Table 1.

Table 1 shows that the number of hits for sleep big data, sleep machine learning, sleep artificial intelligence, and sleep data mining is lower than the other keywords. It would appear that techniques such as big data, machine learning, artificial intelligence, and data mining have not been widely applied to the sleep monitoring research area, although they are now focused in other research areas. Therefore, the combination of these hotspot techniques and sleep monitoring may be a promising research direction and will attract more researchers in the future. To facilitate reading of the data in Table 1, a histogram is drawn, as shown in Figure 2. 
Table 1. Number of occurrences in the field of sleep monitoring system research over 5 years.

\begin{tabular}{|c|c|c|c|}
\hline Keywords & Web of Science, $n$ & PubMed, n & PubMed Central, n \\
\hline Sleep monitoring system & 1416 & 1345 & 23,212 \\
\hline Sleep stage & 3955 & 4561 & 36,146 \\
\hline Sleep phase & 3542 & 2224 & 31,022 \\
\hline Light sleep & 3174 & 2204 & 30,367 \\
\hline Deep sleep & 1172 & 54,438 & 86,653 \\
\hline $\mathrm{REM}^{\mathrm{a}}$ & 5224 & 3220 & 8044 \\
\hline Sleep care & 6760 & 13,154 & 51,882 \\
\hline Sleep quality & 15,517 & 11,616 & 48,324 \\
\hline Wearable device & 9001 & 3379 & 6232 \\
\hline Assistive system & 2735 & 663 & 4912 \\
\hline Noncontact monitoring & 1017 & 205 & 1929 \\
\hline Nonintrusive monitoring & 854 & 73 & 537 \\
\hline Noninvasive monitoring & 6507 & 9355 & 28,298 \\
\hline Smart patch & 561 & 56 & 1462 \\
\hline Medicine skin patch & 82 & 834 & 7232 \\
\hline Portable device & 9501 & 2760 & 13,910 \\
\hline eHealth & 2808 & 1633 & 3613 \\
\hline mHealth ${ }^{\mathrm{b}}$ & 11,712 & 20,583 & 70,836 \\
\hline Homecare & 508 & 404 & 1226 \\
\hline Telecare & 613 & 761 & 934 \\
\hline Telemedicine & 6378 & 10,211 & 7343 \\
\hline Telemonitoring & 921 & 617 & 1575 \\
\hline Body sensor & 12,356 & 2220 & 42,906 \\
\hline Body sensor network & 3368 & 271 & 17,487 \\
\hline Wireless sensor network & 37,771 & 1083 & 5239 \\
\hline Wireless sensor network wearable & 790 & 56 & 1528 \\
\hline Body area network wearable & 592 & 30 & 1982 \\
\hline Personal area network & 1975 & 4013 & 72,117 \\
\hline Personal area network wearable & 67 & 5 & 1389 \\
\hline Sleep monitoring gold standard & 131 & 277 & 4294 \\
\hline $\mathrm{PSG}^{\mathrm{c}}$ & 2036 & 2240 & 4219 \\
\hline $\mathrm{EEG}^{\mathrm{d}}$ & 31,027 & 29,396 & 36,069 \\
\hline $\mathrm{ECG}^{\mathrm{e}}$ & 18,358 & 26,588 & 41,139 \\
\hline Sleep, data processing & 1534 & 437 & 22,206 \\
\hline Sleep, big data & 131 & 69 & 5377 \\
\hline Sleep data mining & 0 & 0 & 4 \\
\hline Sleep machine learning & 277 & 187 & 2807 \\
\hline Sleep artificial intelligence & 27 & 202 & 1194 \\
\hline User needs & 53,375 & 2362 & 40,766 \\
\hline User acceptance & 7711 & 902 & 10,274 \\
\hline User satisfaction & 8892 & 1618 & 11,250 \\
\hline
\end{tabular}


${ }^{a}$ REM: rapid eye movement.

${ }^{b}$ mHealth: mobile health.

${ }^{\mathrm{c}} \mathrm{PSG}$ : polysomnography.

${ }^{\mathrm{d}}$ EEG: electroencephalography.

${ }^{\mathrm{e}}$ ECG: electrocardiography.

Figure 2. Number of results in the field of research on sleep monitoring systems over a 5-year period.

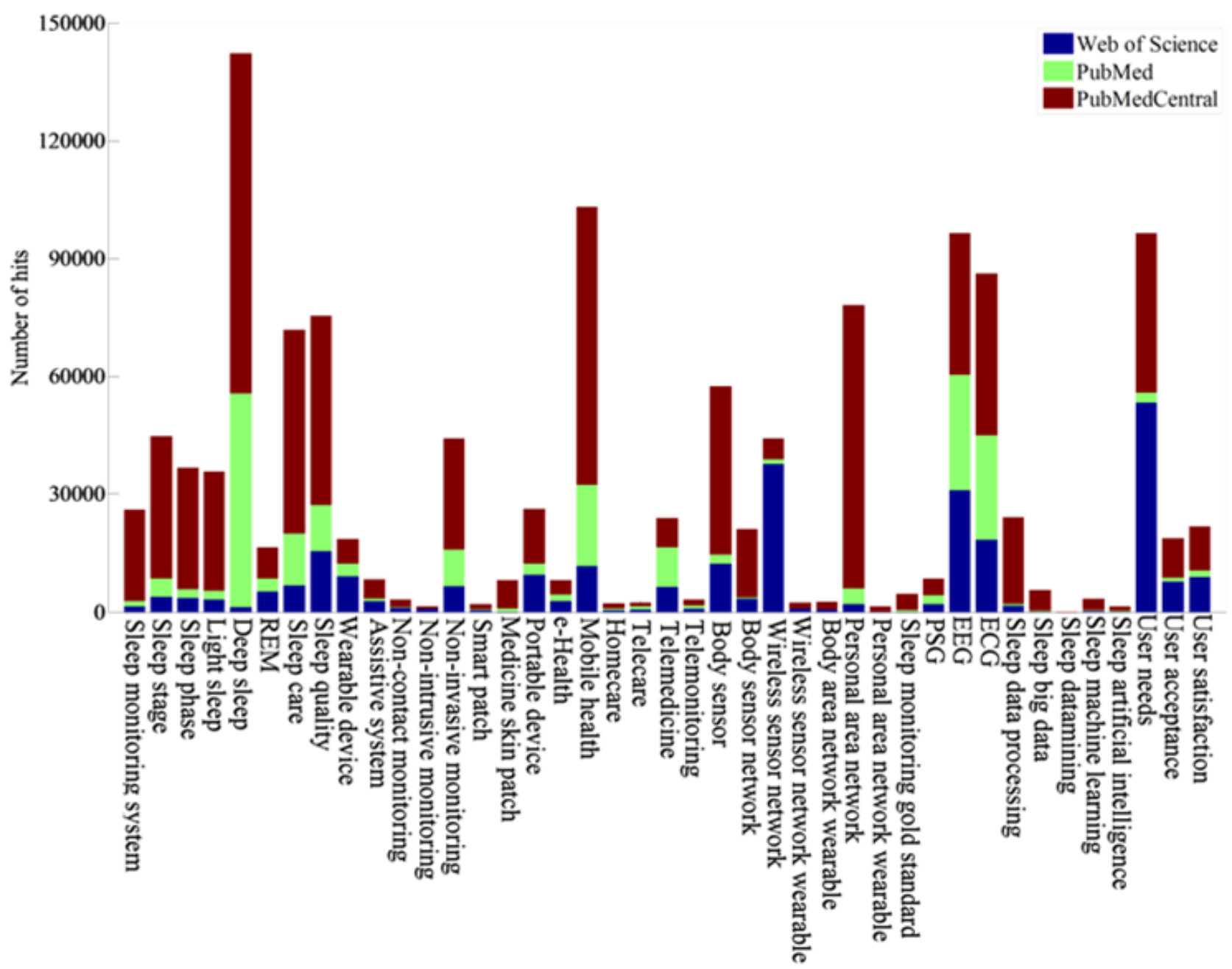

\section{Discussion}

Through the observation and analysis of search results, we found that current and rapidly developing frontier hotspot techniques, such as large data sets, data mining, artificial intelligence, and machine learning, are not yet widely used in the field of sleep monitoring. However, due to the powerful performance and wealth of applications of these techniques, their application in the field of sleep monitoring is expected to be the future development trend and certainly presents great research value and market opportunities.

Big data can be defined by 3 key concepts: volume, velocity, and variety. Volume refers to the amount of data generated and stored. In general, the larger the amount of data, the greater the statistical power for descriptive and predictive analysis. Applied to sleep monitoring systems, it could better describe sleep behavior and predict sleep-related disorders and health status. Velocity refers to the speed of data generation and processing.
Big data are often available in real time. This makes it easier for people to get their sleep monitoring results in a timely manner, while helping subjects or medical staff to respond quickly to abnormalities and emergencies discovered during sleep monitoring. Finally, the term variety refers to different sources, types, and formats of data. Nowadays, more data types are being collected via sleep monitoring systems, including text, audio, image, and video data. Big data allow missing data to be completed through data fusion. This enables comprehensive sleep information to be obtained efficiently. In addition, big data can provide targeted information through the comprehensive and detailed collection of various relevant information, such as age, gender, BMI, place of residence, occupation, and so on. For example, certain age groups, a certain gender, people living in a certain location, people working in a certain profession, and people of a certain body type have a higher rate of poor sleep quality. On the basis of this, it is possible to organize more medical resources in certain areas, and at the same time, more attention in terms of sleep health 
can be given to some people who have a higher rate of poor sleep quality. This will improve the efficiency of the medical system.

Artificial intelligence refers to technology that presents human intelligence through computer programs. Machine learning uses data or previous experience to automatically improve the performance of specific algorithms. Data mining is a computational process that uses artificial intelligence, machine learning, statistics, and databases to discover patterns in relatively large data sets. In general, machine learning is considered a subset of artificial intelligence and consists mainly of data mining. As a tedious and repetitive task, sleep monitoring is well suited to the adoption of these promising and powerful approaches. When applying these approaches, it is more convenient and timely to obtain a large amount and variety of sleep-related data through the continued development of big data technology. This allows these approaches to be used to train more powerful models and to progressively extract higher-level features from the raw data to create a smarter, more efficient, and more convenient sleep monitoring systems.

\section{Current Issues With Sleep Monitoring Systems}

\section{User Needs, Perception, and Acceptance}

A good sleep monitoring system should take into account user needs, perception, and acceptance before it is designed. User needs for sleep monitoring systems are diverse. These could include obtaining accurate and complete information about sleep. These needs could be met by professional medical instruments such as PSG and EEG. In addition, the user needs could also obtain auxiliary reference information, that is, only a small amount of key information such as sleep duration, number of awakenings, proportion of different sleep stages, and even only a summary of the sleep score. These needs are typically met by various apps in consumer electronics and smartphones with sleep monitoring functions. Compared with professional medical devices, this type of commercial product takes better account of the user's perception and is usually noninvasive, nonintrusive, or even contact free. The user's perception of the sleep monitoring system is closely related to the number of electrodes or sensors attached to the body, the position, and the method of attachment on the body.

For the number of electrodes or sensors, the fewer the number, the better the user's perception. For the position of the attachment, it is preferable to attach it to the distal limbs such as the wrist, fingers, ankle, instep, and toes rather than to the main body, face, and head. The method of attachment to the body may be by using adhesive tape or a belt, such as a chest belt. In general, adhesive bonding may give a better user perception than a belt because there is less contact area with the body and less restraint on the body. User acceptance of sleep monitoring systems depends on the satisfaction of the user's needs and perception. Usually the satisfaction of user needs and the satisfaction of user perception are contradictory. To meet user needs as much as possible, more complete and accurate human physiological information needs to be collected, which often means that more sensors need to be attached to more body positions, often worsening user perception. Therefore, the design of a good sleep monitoring system has to find a compromise between users' needs and their perception to achieve a good user perception, which is usually related to ease of use while trying to meet user needs as much as possible.

\section{Effectiveness}

Although PSG is the gold standard for sleep monitoring, it is expensive, highly invasive, and complicated to perform. PSG monitoring is not easily accessible, especially in developing countries [37]. Owing to the many limitations of PSG, most people are only subject to PSG monitoring for one night. However, monitoring at night is not sufficient to determine the actual sleep status. To improve effectiveness and obtain appropriate follow-up, long-term, at-home monitoring is necessary.

Guettari et al [38] proposed a system based on one thermal sensor is used over a long period of time to supervise changes in sleep quality and can be used at home and consulted remotely by sleep medicine experts. Changes in sleep quality derived from long-term monitoring are very useful for assessing sleep health. Using existing equipment daily for sleep monitoring is found to be an effective approach, such as sleep monitoring using our smartphone router. Liu et al [39] proposed monitoring vital signs of breathing and heart rate during sleep using a single Wi-Fi access point (such as a router) and a single Wi-Fi device (PC or smartphone) without any wearable or dedicated devices. Thus, the system has the potential to be widely deployed and to perform continuous long-term monitoring. Smartphone apps are considered a good choice for large-scale, low-cost, and long-term sleep monitoring, which will improve effectiveness and accuracy [21,40]. Sleep Hunter [41] is a mobile service that uses smartphones' built-in sensors. It is implemented on the Android platform and can detect the transitions between sleep stages for monitoring sleep quality and the intelligent wake-up call, which wakes users in light sleep. The ability to perform long-term monitoring is important for the effectiveness of a sleep monitoring system. Long-term monitoring is essential for reliable results and early detection of abnormal sleep changes. To do this, sleep monitoring systems should be as inexpensive, easy to use, and easily accessible as possible.

\section{Interoperability}

Sleep monitoring devices are useful in health care. The value of these devices will increase if sleep monitoring system software apps can seamlessly collect medical data and upload the data to a database. The ISO/IEEE11073 (X73) family of interoperability standards was originally designed for point-of-care clinical environments. The latest branch of X73, X73 for personal health devices (X73PHD), enables the development of interoperable personal health ecosystems and brings benefits to both technology producers (design cost reduction, experience sharing, and marketing facilities) and users (plug and play, accessibility, ease of integration, and prices) [42]. OpenICE is an open-source software project of the Medical Device Plug-and-Play Interoperability Program at Massachusetts General Hospital, leveraging much of the program's research performed since 2004 to support 4 distinct user groups: use case demonstrations, clinical adoption, regulatory science, and commercial adoption [43]. Data sharing and interoperability are positive for users, researchers, 
physicians, and businesses. With the development and popularization of big data technology, improving interoperability is a hotspot in sleep monitoring system research and will be the trend for future development.

\section{Hardware and Software Considerations}

The main considerations for sleep monitoring system hardware focus on 3 aspects: cost, comfort, and convenience, which could be the determining factors for the acceptance of implementation. In terms of cost, the equipment should be affordable for most people. In addition, for devices that require frequent maintenance, such as the need for frequent replacement of specific components and the consumption of specific reagents or materials, their costs should be considered. For devices designed to use disposable batteries instead of rechargeable batteries, the energy consumption should be taken into account, as frequent battery replacement will significantly increase the cost of use. In terms of comfort, contactless systems have the greatest advantage, but for contact systems, the emphasis is on wireless, miniaturization, and weight reduction. The comfort aspect includes ease of implementation and maintenance convenience. In terms of the convenience of implementation, daily implementation does not have to be complex and time consuming. The main objective is to allow users to carry out the application themselves without the intervention of professional technicians. Generally, in terms of maintenance convenience, the longer the maintenance interval, the easier the operations are.

The main considerations for sleep monitoring system software are two-fold: effectiveness and efficiency. First, the sleep monitoring software must be able to effectively process the data collected to obtain the most accurate monitoring results. In terms of efficiency, this includes temporal efficiency and energy efficiency. It is very important for real-time sleep monitoring system processing to consider temporal efficiency. The cost of the execution time must be short enough to meet the real-time requirement.

For non-real-time sleep monitoring systems that process data after the end of monitoring, time efficiency is also of great importance. After sleep, users tend to be concerned about the results obtained. Waiting time will have an impact on the user experience, so the shorter the processing time, the better. Energy efficiency depends on 2 aspects: optimization of the algorithm and sleep or wake programming for the hardware. If the algorithm can be optimized well, it will significantly reduce the energy consumption for the execution of the algorithm. Furthermore, with reasonable sleep or wake programming of the hardware, unnecessary energy consumption can be avoided.

\section{Medical, Wellness, and Quality-of-Life Benefits}

Sleep quality is a crucial factor for human health and quality of life. There is growing recognition of the harmful effects of poor sleep quality and sleep disorders. Patients with sleep disorders are prone to chronic diseases such as obesity, diabetes, and hypertension. The use of sleep monitoring systems could reduce the incidence of sleep-related illnesses or illnesses could be predicted by sleep through long-term monitoring and trend analysis. McHill et al [44] demonstrated the relationship between obesity and sleep time. Lee et al [45] examined the impact of sleep quantity and sleep quality on blood glucose control in type 2 diabetes. Fuchs et al [46] showed that OSA is a clear risk factor for resistant hypertension. The application of sleep monitoring system can overcome infrequent clinical visits that may not detect transient events that predict dangerous future events. Early diagnosis through long-term trend analysis could prevent the potential severity of a disease. These analyses could provide an instant diagnosis of acute events, issue alerts to health care professionals, and reduce the time of intervention through telediagnosis and teletherapy. Some typical sleep disorders, such as sleep apnea, restless leg syndrome, and periodic limb movement disorders can be detected in time through sleep monitoring. Unfortunately, people with sleep disorders such as OSA tend to go undiagnosed [47] because they are usually not even aware that sleep apnea events have occurred. This lack of awareness of symptoms during sleep is a serious health problem for modern life [48]. The early signs of these disorders could be monitored and treated with mild medications [49].

\section{Cost, Psychological, and Socioeconomic Barriers}

Wireless patches, wristbands, chest belts, headbands, or other wearable devices that connect a sleeper to formal or informal caregivers, a data center or call center, who can then notify medical services in the event of abnormal sleep, are affordable and reliable. This technology has been available for more than 15 years, but despite its affordability [50], its adoption is minimal in almost all countries. Wearing permanent health care mobile devices and systems has psychological effects on patients. Significant barriers limit the widespread use of these systems due to the lack of studies on testing smart wearable systems by end users who provide feedback and preferences [51]. The high cost of current sleep monitoring system services limits their expansion. Wireless networks are another barrier to sleep monitoring system deployment. Until the end of 2019, the global internet penetration rate was only $58.7 \%$ [52]. Consequently, access to services via internet is not always available. People affected by sleep disorders may have difficulties in finding adequate sleep monitoring devices and services to support them in monitoring the quality of their sleep. Economic and social issues also need to be addressed to ensure that the market for sleep monitoring systems is opened up. A sound analysis of the costs and benefits of sleep monitoring systems has not been conducted. Some studies focus solely on system technology and performance [40,53]. Sociotechnical design science needs to be taken into consideration to ensure that sleep health care meets the needs of society. Ultimately, Coiera [54] argued that it is the beliefs and values of our culture that shape what we will create and what we will dream about. A total of 4 rules govern the design of health services: (1) technical systems have strong social consequences, (2) social systems have technical consequences, (3) we do not design technology; designing sociotechnical systems does not just mean designing technology, and (4) the design of sociotechnical systems must consider the way in which people and technologies interact. 


\section{Privacy, Ethics, and Legal Barriers}

With the continuous development of sleep monitoring technology, the collection of user information via sleep monitoring system has become increasingly detailed and diverse. At the same time, it has gradually evolved from traditional overnight monitoring to long-term monitoring. This series of developments has improved the accuracy and reliability of sleep monitoring but has significantly increased the risk of leakage of user privacy information. To protect the privacy of users, the traditional method is to provide informed consent before receiving sleep monitoring, and data collection can only take place once the user has signed the informed consent. Consent is normally used to authorize a single study, and there are no specific regulations for data sharing in the research community. Given the high value and gradually popular trend of big data apps, privacy issues related to data sharing need to be addressed urgently by legislators.

\section{Impact of Sleep Monitoring Systems on Society}

Sleep disorders affect a significant part of the population [10-12]. The socioeconomic consequences can be dramatic. It includes drowsiness while driving, drowsiness in the workplace, and cardiovascular diseases [55]. Surantha et al [56] argued that sleep quality monitoring is one of the solutions to maintaining sleep quality and preventing chronic diseases, mental problems, or accidents caused by sleep disorders.

On the basis of these considerations and issues, many types of sleep monitoring systems have been developed. The features of these are detailed in the following section.

\section{Sleep Monitoring System Features \\ Conventional Sleep Monitoring Systems}

\section{Polysomnography}

Polysomnography (PSG) is the gold standard in sleep assessment introduced in the 1960s as a tool for assessing sleep disorders.
The subject equipped with a PSG is illustrated in Figure 3. A PSG records a minimum of 12 channels requiring a minimum of 22 wires attached to the patient. These channels vary in each laboratory and can be adapted to meet the physician's requirements. There are a minimum of 3 channels for the EEG, 1 or 2 measure airflow, 1 or 2 are for chin muscle tone, 1 or more for leg movements, 2 for eye movements (EOG), 1 or 2 for heart rate and rhythm, 1 for oxygen saturation, and 1 for each waist belt, which measures movements of the chest wall and upper abdominal wall. Belt motion is usually measured using piezoelectric sensors or respiratory inductance plethysmography. Breathing amplitude is often measured with the temperature changes that occur with breathing, as measured by a thermistor or thermocouple placed in the path of the airflow (nose and mouth). Body movement was measured by using EMG. Oximetry is adopted to measure oxygen saturation levels in the blood by passing infrared light through the finger and measuring absorption patterns (made by the oxygen-carrying pigment, hemoglobin, in the blood). The body position sensor is used to distinguish between lying, standing, and lateral positions during sleep.

Although PSG provides the most accurate and objective measurement of sleep, specialized equipment, an elaborate facility, and dedicated and experienced PSG technologists are required to perform and analyze recordings, which are costly and labor intensive. This technique is not practical for large-scale and long-term sleep monitoring [57].

Figure 3 shows the standard configuration of a polysomnogram. In Figure 3, the patient lies in a bed with sensors attached to the body. In Figure 3, the polysomnogram recording shows the blood oxygen level, the respiratory event, and the REM sleep stage over time. 
Figure 3. The PSG sleep monitoring - National Heart Lung and Blood Institute (NIH), November 2013.

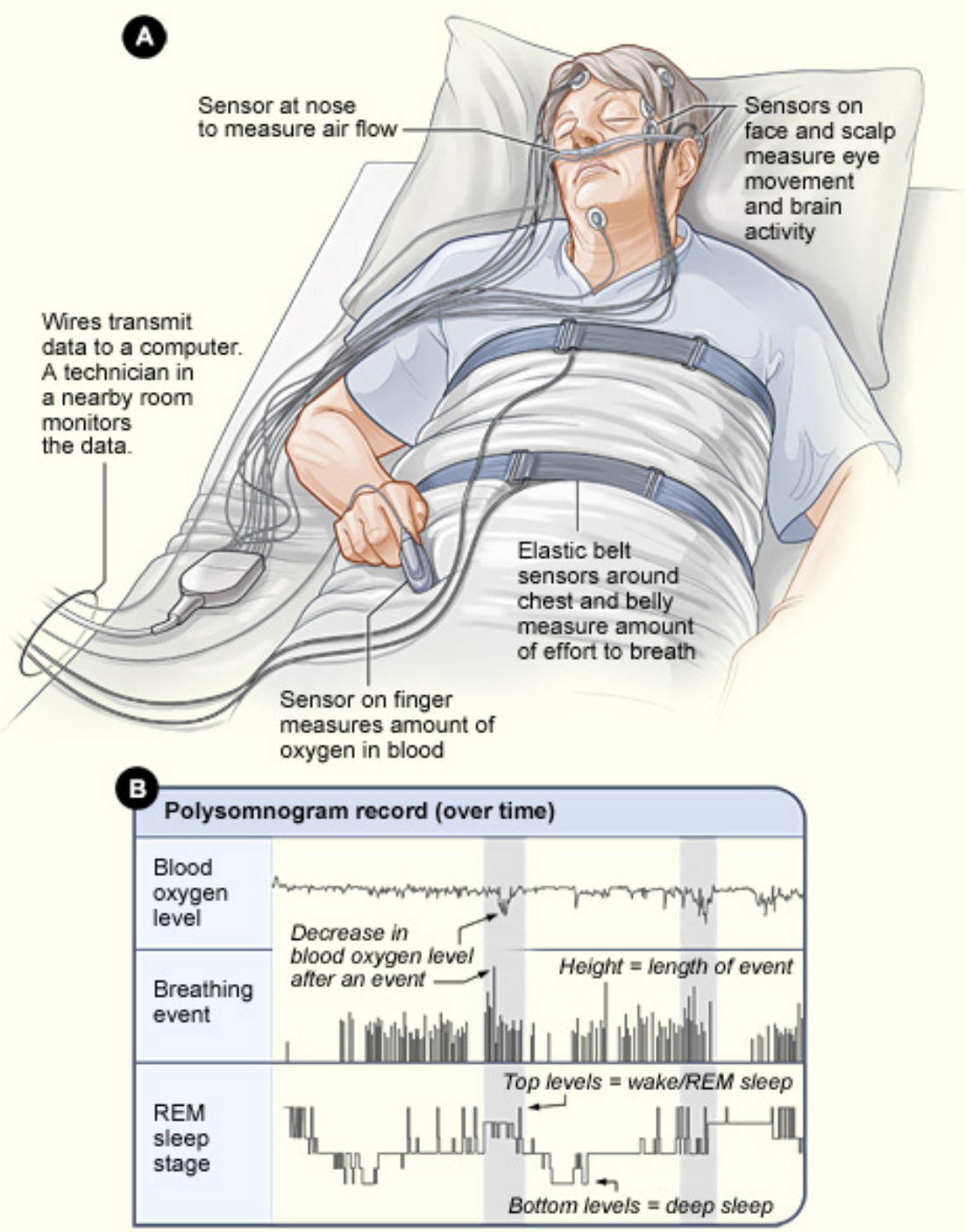

\section{Electroencephalography}

EEG is an electrophysiological monitoring method that records electrical activity of the brain using electrodes placed along the scalp to measure the voltage fluctuations resulting from ionic current in the neurons of the brain [58]. The EEG signal is the most important signal in the classification of sleep stages [59].

Different sleep stages are characterized by different brain activities that can be detected by EEG recordings. The EEG patterns of the different sleep stages are shown in Figure 4 Stage 1 is the transition stage between wakefulness and sleep. It usually lasts between 1 and $5 \mathrm{~min}$. This stage consists of a low voltage EEG trace with well-defined alpha (Figure 5) and theta (Figure 5) activity, occasional vertex peaks, and slow eye movements. This stage, on average, represents $4 \%$ to $5 \%$ of total sleep and is free of sleep spindles (Figure 5) and $\mathrm{K}$-complexes (Figure 5). Stage 2 is the baseline of sleep and is characterized by the occurrence of sleep spindles and $\mathrm{K}$-complexes and a relatively low voltage, mixed frequency EEG background. In addition, high voltage delta waves may account for up to $20 \%$ of stage 2 epochs. Stage 3 is a period in which at least $20 \%$ and no more than $50 \%$ of sleep consists of EEG signals with a frequency less than or equal to $2 \mathrm{~Hz}$ and an amplitude greater than $75 \mu \mathrm{V}$ (delta waves; Figure 5). Stage 4 is quite similar to stage 3, except that delta waves cover $50 \%$ or more of the recording. Stage 4 typically represents $12 \%$ to $15 \%$ of total sleep time.

Stages 3 and 4 together are also called deep sleep or slow wave sleep (SWS), and it is the most restorative part of sleep. REM is the sleep stage in which dreams occur and makes up $20 \%$ to $25 \%$ of a normal night's sleep. It is well known that the incidence of rapid eye movements under closed eyelids, motor atonia, and low voltage EEG patterns. During REM sleep, the brain activity is reversed from stage 4 to a pattern similar to that in stage 1 . The characteristics of each sleep stage are summarized in Table 2. Although the EEG is accurate for determining sleep stages, the complexity and intrusiveness of the user make it difficult to achieve large-scale, long-term, and home sleep monitoring. 
Figure 4. Typical EEG pattern for different stages of sleep [60].
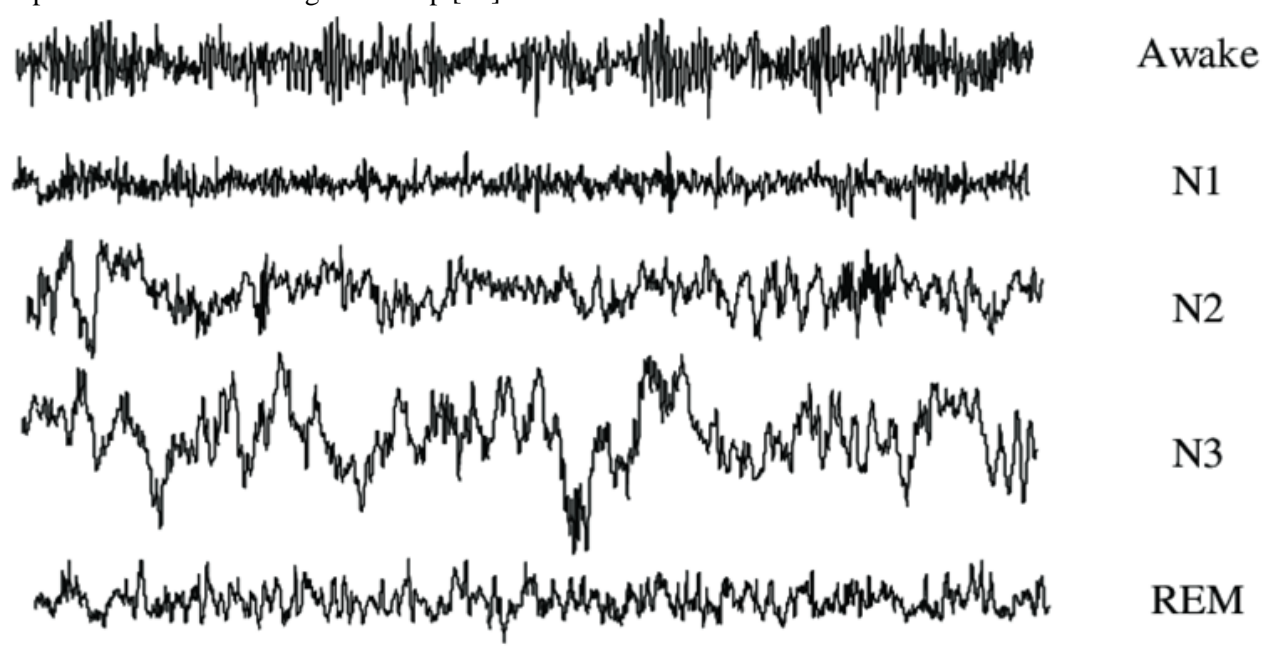

Figure 5. Typical EEG wave types.

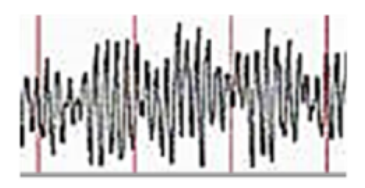

a. Alpha wave

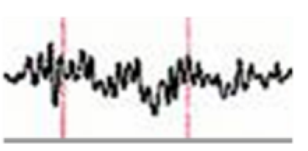

d. Spindle wave

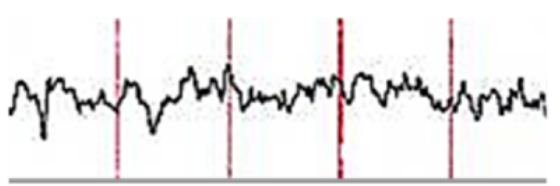

b. Theta wave

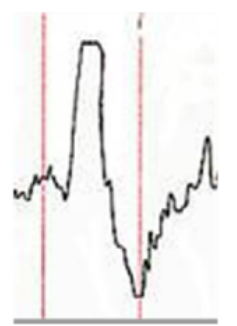

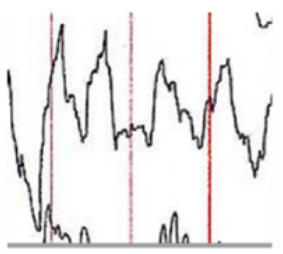

c. Delta wave

e. K-complex wave

Table 2. Characteristics of each stage of sleep.

\begin{tabular}{|c|c|c|c|c|}
\hline Sleep stages & Proportion of sleep, $\%$ & $\mathrm{EEG}^{\mathrm{a}}$ frequency $(\mathrm{Hz})$ & EEG amplitude (mv) & EEG percentage (one screen) \\
\hline Awake & $<5$ & $15-50$ & $<50$ & $\alpha>50 \%$ \\
\hline $\mathrm{N} 1$ & $2-5$ & $4-8$ & $50-100$ & Theta wave $>50 \%$ or alpha wave $<50 \%$ \\
\hline $\mathrm{N} 2$ & $45-55$ & $4-15$ & $50-150$ & Delta wave $<20 \%$; K-complex $>1.7 \%$ \\
\hline $\mathrm{N} 3$ & $3-8$ & $2-4$ & $100-150$ & Delta wave $20 \%$ to $50 \%$ \\
\hline N4 & $10-15$ & $0.5-2$ & $100-200$ & Delta wave $>50 \%$ \\
\hline REM $^{\mathrm{b}}$ & $20-25$ & $15-30$ & $<50$ & EEG with mixed wave \\
\hline
\end{tabular}

${ }^{\mathrm{a}} \mathrm{EEG}$ : electroencephalography.

${ }^{\mathrm{b}} \mathrm{REM}$ : rapid eye movement.

\section{Electrocardiography}

Electrocardiography (ECG) is the process of recording the electrical activity of the heart over a period of time using electrodes placed on the skin. These electrodes detect tiny electrical changes on the skin that result from the electrophysiological pattern of depolarization and repolarization of the heart muscle with each heartbeat. In a conventional 12-lead ECG, 10 electrodes are placed on the patient's limbs and on the surface of the chest. The correlation behavior in the heartbeat rate significantly differed for light sleep, deep sleep, and REM sleep. During deep sleep, the heartbeat rate is reduced, whereas a relative increase is observed in REM sleep [61]. 
Furthermore, spontaneous movements during sleep are preceded by an increase in heart rate [62]. These observations indicate a functional link between cardiac activities and sleep stages. As with PSG and EEG, the complexity, high equipment, and expertise requirements of the standard ECG are barriers to its use as a large-scale, long-term, home sleep monitoring method.

\section{Wireless Body Area Network}

\section{Introduction}

The wireless body area network (WBAN) is a wireless sensor network that aims to monitor the vital signs and physiological information of the user by deploying sensors on or next to the human body. Parameters acquired from the WBAN can include brain waves, heart rate, body movements, body temperature, blood oxygen saturation level, sound, and so on, or environmental conditions such as temperature, brightness, noise level, and humidity. Owing to advances in sensor and communication technology, WBAN enables the exchange of information or commands over short distances between sensor components. Moreover, remote data transmission or control between the sensor components and the database or control center is also available based on WBAN. Such features make the WBAN a very suitable tool for performing continuous monitoring tasks without requiring too much manual intervention, which meets the requirements of sleep monitoring. As a result, many sleep monitoring systems have been developed by researchers and technicians based on the WBAN.

WBAN technology is highly valued in the fields of medical sciences and human health care [63]. In the health care field, WBAN has established itself as a leading technology capable of providing real-time patient health monitoring in hospitals, asylums, and even at home [64]. WBAN allows the removal of cables and the delocalization of instrumentation and intelligence to the sensor nodes themselves, which is useful for establishing a nonintrusive, portable, continuous home sleep monitoring system [55]. Currently, WBAN-based sleep monitoring system has attracted increasing attention from researchers worldwide [65-67]. Similar to the evolution of the WBAN, the trends in sleep monitoring system are miniaturization, intelligence, and long-term monitoring capability. In this section, we have selected a few representative works on WBAN-based sleep monitoring systems in recent years, which we briefly present from a hardware and software perspective.

\section{Hardware Implementation}

A WBAN-based sleep monitoring system is a sensor network application in which the sensor is an essential piece of hardware. The choice of sensor determines the type of body parameters that will be acquired, and the position of the sensors directly influences the efficiency, quality of data acquisition, and user acceptance. For these reasons, we list the type and position of sensors used in several works, specify the possible description of sleep phases, and briefly analyze the advantages and drawbacks of each type of sensor, as presented in Multimedia Appendix 1 [68-99]. Table 3 lists the sensors used in each study.

As shown in Multimedia Appendix 1 [68-99], the accelerometer is the most commonly used sensor in these works, usually placed on the wrist or chest or close to both positions. The microphone was adopted only once among these works. However, the microphone is a widely used sensor in sleep apnea monitoring $[63,104,105]$. As a sound recording sensor, the microphone is useful for detecting snoring or even abnormal breathing [106], which are also important physiological parameters related to the sleep state. Both the ECG sensor and the pulse sensor are used for heart rate monitoring, but due to different detection principles, their positions are different. Multimedia Appendix 1 [68-99] shows that in most cases, the ECG sensor is placed near the chest, whereas the pulse sensor is placed near the wrist. Thus, for user acceptance, the pulse sensor is better than the ECG sensor.

Both the accelerometer and the thermopile sensor can be used for motion detection, but they have their own advantages. In terms of user acceptance, the accelerometer should generally be attached to the user's body, but the thermopile sensor is a noncontact sensor, so the thermopile sensor is preferable. However, with regard to measurement accuracy, thermopile sensors are easily disturbed by the user's coatings, such as duvets, which affect the measurements. In addition, thermopile sensors can only monitor effectively in a limited and fixed area. It is difficult for thermopile sensors to specifically measure the movement of certain parts of the body, such as measuring only leg movement to detect periodic leg movements during sleep. As a result, the accelerometer outperforms the thermopile sensor. In short, the type of sensor to be chosen depends on the application scenario and specific requirements. 
Table 3. Choice of sensor for different works related to sleep monitoring.

\begin{tabular}{|c|c|c|c|c|c|c|c|}
\hline Sources & Accelerometer & Pressure sensor & $\begin{array}{l}\text { Temperature } \\
\text { sensor }\end{array}$ & $\begin{array}{l}\text { Thermopile sensor } \\
\text { (Infrared) }\end{array}$ & Microphone & $\mathrm{ECG}^{\mathrm{a}}$ sensor & Pulse sensor \\
\hline Kalkbrenner et al [70] & $\mathfrak{J}^{\mathrm{b}}$ & $-^{c}$ & - & - & $\checkmark$ & - & - \\
\hline Guettari et al [38] & - & - & - & $\checkmark$ & - & - & - \\
\hline Seba et al [100] & $\checkmark$ & - & $\checkmark$ & $\checkmark$ & - & - & - \\
\hline Velicu et al [68] & $\checkmark$ & - & - & - & - & $\checkmark$ & \\
\hline Suzuki et al [96] & $\checkmark$ & - & $\checkmark$ & - & - & $\checkmark$ & $\checkmark$ \\
\hline Suzuki et al [76] & $\checkmark$ & - & - & - & - & - & $\checkmark$ \\
\hline Saad et al [92] & $\checkmark$ & - & $\checkmark$ & - & - & - & $\checkmark$ \\
\hline Sadek et al [98] & - & $\checkmark$ & - & - & - & - & - \\
\hline Sadek et al [101] & - & $\checkmark$ & - & - & - & - & - \\
\hline Lee et al [102] & $\checkmark$ & - & - & - & - & $\checkmark$ & - \\
\hline Chan et al [97] & $\checkmark$ & - & - & - & - & $\checkmark$ & - \\
\hline Samy et al [103] & - & $\checkmark$ & - & - & - & - & - \\
\hline
\end{tabular}

${ }^{\mathrm{a}} \mathrm{ECG}$ : electrocardiography.

$\mathrm{b}_{\text {The sensor is included. }}$

${ }^{\mathrm{c}}$ The sensor is not included.

\section{Software and Algorithm Processing}

Software or algorithms are used to process the data collected by the hardware. Table 4 presents the algorithms, software, and system results illustrated in several books or articles.

Data or signal processing algorithms usually include spectral analysis, wavelet transformation, empirical mode decomposition (EMD), and various varieties of filters. Many sleep-related physiological signals, such as EEG and ECG, are nonstationary. A wavelet analysis is very useful for processing nonstationary signals, which is why it has been adopted by many researchers specializing in sleep monitoring. EMD, proposed by Huang et al [109], is usually used to extract breathing and heartbeat signals from measured data. Unlike wavelet-based decomposition methods, this method is data-driven and does not require a parent wavelet to be defined beforehand. With this technique, any complicated signal can be decomposed into a defined number of high- and low-frequency components, called intrinsic mode functions. This technique is suitable for the analysis of nonlinear and nonstationary biosignals [110] and can extract local temporal structures such as heartbeats superimposed on respiration signals [111]. In sleep monitoring, several types of biosignals of different frequencies are acquired simultaneously. Therefore, filters are effective and simple tools for signal discrimination that are widely adopted in this field.

The classification algorithm is usually used for the classification of sleep stages. Sleep stage classification is an important and common output of sleep monitoring system. Although sleep stages include stages 1, 2, 3, and 4 and stage REM according to the AASM [18], most research classifies sleep stages in a simpler way as wake, lightsleep (stages 1 and 2), deep sleep (stages 3 and 4), REM [108] or wake, NREM (stages 1, 2, 3, and 4), REM [102], or some other similar way. This simplification of sleep stages involves balancing the difficulty of the task with the application requirements. Commonly used classifiers include random forest (RF), support vector machine (SVM), multilayer, feedforward neural network (NN), linear discriminant analysis (LDA), decision tree (DT), and Bayes. Some papers compare the performance of several classifiers in their work to find the best one [101,108]. 
Table 4. Implementation of software or algorithm in different works.

\begin{tabular}{|c|c|}
\hline Sources & Involved algorithms or software \\
\hline \multirow[t]{3}{*}{$\begin{array}{l}\text { Kalkbrenner } \\
\text { et al [73] }\end{array}$} & $\begin{array}{l}\text { 1. An FIR }{ }^{\mathrm{a}} \text { bandpass filter with boundaries between } 200 \text { and } 2000 \mathrm{~Hz} \text { was used on } \\
\text { the initial raw tracheal body sound signal acquired by microphone to obtain a pure } \\
\text { breathing sound signal }\end{array}$ \\
\hline & $\begin{array}{l}\text { 2. A bandpass filter with the boundaries between } 5 \text { and } 30 \mathrm{~Hz} \text { was applied on the } \\
\text { initial raw tracheal body sound signal acquired by microphone to suppress breathing } \\
\text { and most of the artifacts to get heart beat sound }\end{array}$ \\
\hline & $\begin{array}{l}\text { 3. } A \mathrm{LD}^{\mathrm{b}} \text { classifier was used on cardiorespiratory features and movement features } \\
\text { for automated sleep staging }\end{array}$ \\
\hline \multirow[t]{5}{*}{$\begin{array}{l}\text { Sadek et al } \\
\text { [98] }\end{array}$} & $\begin{array}{l}\text { 1. Wavelet decomposition was used on microbend fiber optic sensor data to achieve } \\
\text { the measuring of heart rate }\end{array}$ \\
\hline & $\begin{array}{l}\text { 2. Third-order polynomial fit and Savitzky-Golay smoothing was used on microbend } \\
\text { fiber optic sensor data to achieve the measuring of respiratory rate }\end{array}$ \\
\hline & $\begin{array}{l}\text { 3. Adaptive thresholding method was used on SD of the respiratory signal for apnea } \\
\text { or nonapnea classification }\end{array}$ \\
\hline & 4. Chebyshev type-I bandpass filter was used on microbend fiber optic sensor data \\
\hline & $\begin{array}{l}\text { to extract } \mathrm{BCG}^{\mathrm{e}} \text { and respiratory signals } \\
\text { 5. The } \mathrm{MODWT}^{\mathrm{f}} \text { with the multiresolution analysis was used on microbend fiber optic } \\
\text { sensor data to estimate heart rate }\end{array}$ \\
\hline
\end{tabular}

Guettari et al 1. SAX $X^{\mathrm{g}}$ method was used on thermal sensor data for segmentation processing of the [38] thermal signal

2. $\mathrm{SOM}^{\mathrm{h}}$ algorithm-Kohonen maps is used on features of thermal signal segmentation level, thermal signal segmentation duration and the variance of each thermal signal segmentation for achieving classification

Outputs

1. Sleep and wake classification

2. Wake, $R^{2} M^{\mathrm{c}}$, and NREM ${ }^{\mathrm{d}}$ classification

3. Wake, REM, light sleep, and deep sleep classification

Heart rate, respiratory, and apnea 


\begin{tabular}{|c|c|c|}
\hline Sources & Involved algorithms or software & Outputs \\
\hline $\begin{array}{l}\text { Suzuki et al } \\
{[96]}\end{array}$ & $\begin{array}{l}\text { 1. Silmee framework provides basic functionality of Silmee system by locating Silmee } \\
\text { sensor node, smartphone (or tablet or wearable terminal) and cloud server } \\
\text { 2. Silmee firmware provides vital signal processing capabilities such as noise reduc- } \\
\text { tion, important information extraction, or data compression } \\
\text { 3. Silmee API }{ }^{\mathrm{O}} \text { : This API provides basic information to realize wide-variety of smart } \\
\text { healthcare MW' and apps } \\
\text { 4. Silmee MWs are located in smartphone (or tablet or wearable terminal) or in health } \\
\text { care cloud server. The MWs provide less medical expert API than Silmee API. } \\
\text { For example, determination of REM and non-REM sleep, which is a popular term, } \\
\text { is one of Silmee MW API, which is calculated by R-R intervals information includ- } \\
\text { ed in the Silmee API }\end{array}$ & $\begin{array}{l}\text { ECG wave, pulse wave, body temperature } \\
\text { and body movements were measured by the } \\
\text { set and send to a smartphone using a Blue- } \\
\text { tooth wireless connection }\end{array}$ \\
\hline $\begin{array}{l}\text { Suzuki et al } \\
{[76]}\end{array}$ & $\begin{array}{l}\text { 1. The Cole algorithm for wake and sleep identification from the amount of activity } \\
\text { data } \\
\text { 2. Fast Fourier transformation (FFT) is executed for the even-interval pulse-to-pulse } \\
\text { intervals to get the frequency spectrum } \\
\text { 3. The k-means clustering method is adopted to classify sleep stages }\end{array}$ & $\begin{array}{l}\text { Wristwatch-shaped physiological sensor } \\
\text { that monitors user's wrist motion and pulse } \\
\text { wave interval }\end{array}$ \\
\hline Lee et al [102] & $\begin{array}{l}\text { 1. To capture the respiratory signal, first-order derivation is used to compensate for } \\
\text { the drifting phenomenon of pressure sensor } \\
\text { 2. A low-pass filter is applied to eliminate short-term fluctuations in respiration signals } \\
\text { 3. Sum all the pixels in the lower half of the pressure image and mark a leg movement } \\
\text { when a significant drop or increase in pressure is detected } \\
\text { 4. A simple thresholding technique for movement reporting }\end{array}$ & $\begin{array}{l}\text { Classification of sleep stages: } \\
\text { 1. Wake } \\
\text { 2. NREM } \\
\text { 3. } \\
\text { REM }\end{array}$ \\
\hline $\begin{array}{l}\text { Beattie et al } \\
{[108]}\end{array}$ & $\begin{array}{l}\text { The Scikit library used to explore different types of classifiers: LD classifiers, quadratic } \\
\text { discriminant classifiers, RF, and SVM approaches, and the LD classifier achieved the } \\
\text { best performance }\end{array}$ & $\begin{array}{l}\text { Classification of sleep stages: } \\
\text { 1. Wake } \\
\text { 2. Light (N1 or N2) sleep } \\
\text { 3. Deep (N3) sleep } \\
\text { 4. } \\
\text { REM }\end{array}$ \\
\hline
\end{tabular}

${ }^{\mathrm{a}}$ FIR: Finite impulse response.

${ }^{\mathrm{b}} \mathrm{LD}$ : linear discriminant.

${ }^{\mathrm{c}}$ REM: rapid eye movement.

${ }^{\mathrm{d}}$ NREM: nonrapid eye movement.

${ }^{\mathrm{e}} \mathrm{BCG}$ : ballistocardiography.

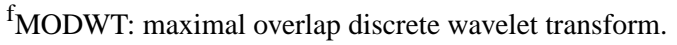

${ }^{\mathrm{g}} \mathrm{SAX}$ : symbolic aggregate approximation.

${ }^{\mathrm{h}}$ SOM: self-organizing map.

${ }^{\mathrm{i}}$ IDE: integrated development environment.

${ }_{\text {RF: random forest. }}$

${ }^{\mathrm{k}} \mathrm{SVM}$ : support vector machine.

${ }^{1} \mathrm{NN}$ : neural network.

${ }^{m}$ LDA: linear discriminant analysis.

${ }^{\mathrm{n}}$ DT: decision tree.

${ }^{\circ} \mathrm{API}$ : application programming interface.

${ }^{\mathrm{p}} \mathrm{MW}$ : middleware.

\section{Research Prototypes}

\section{Noncontact Methods}

Seba et al [100] discussed the development of a new approach to sleep analysis. This system, based on temperature monitoring (patient and ambient), aims to be integrated into the telemedicine platform developed in the framework of the Smart-EEG project by the SYEL_-SYstèmes ELectroniques team. The proposed method is based on the thermal signature to classify the activity into 3 classes: awakening, calm sleep, and agitated sleep by k-means clustering. A thermopile sensor (TMP007) was placed above the bed at a distance close to $2 \mathrm{~m}$ to measure the upper Bed+Patient temperature. A thermal camera giving images in medical format but also information on the target temperature according to a spatial distribution is used to label the different events related to changes in the patient's posture in the bed by visual analysis of an expert. An inertial unit is used to obtain the wrist acceleration in 3 axes to compare the responses of the thermopile sensor. The system measured the wrist, distal, and proximal skin temperatures using IButtons [112]. The day and night alternation corresponds, on the one hand, to the alternation between wakefulness and sleep and, on the other hand, to the alternation between high and low temperature. During sleep, 
the body temperature decreases whereas it increases during the day. Skin temperature, unlike the body temperature, increases during sleeping and decreases after awakening. The work in [113] examined possible mechanisleep monitoring system linking rhythms in sleep and core body and skin temperature, focusing on the causal effects of changes in core and skin temperature on sleep regulation. Several studies refer to the links between body temperature and sleep $[112,114]$. This work gave a figure of an example of classification for sleep base on thermal data.

Guettari et al [38] presented the design and first evaluation of a new monitoring system based on contactless sensors to estimate sleep quality. A passive thermopile sensor fixed on the wall produces thermal signals to detect human presence in the bed and then to estimate the quality of sleep. The Symbolic Aggregate Approximation (SAX) method has been implemented [115], which uses Gaussian window in the thermal signal segmentation processing. Each segment is generated by the SAX method based on a segmentation of the midvariance and then by identifying its sleep phase. The system extracted 3 features: the duration of the thermal data segment, the variance of the thermal segment of each segment, and the level of each segment. The Kohonen self-organized map (SOM) [116] was used to classify the signal segments into 3 sleep phases: deep or paradoxal sleep $(\mathrm{R}, \mathrm{N} 3)$, agitated or light sleep $(\mathrm{N} 1, \mathrm{~N} 2)$, and awake phase $(\mathrm{W})$. It synchronized the thermal signal with the sleep stage labels based on the physiological parameters measured by the PSG with a hypnogram being established manually by the physicians. This study involved 13 patients, 11 people for learning the SOM model, and 2 other patients for evaluation of the learned SOM model. In total, $87 \%$ (40/46) of evaluation results showed good classifications.

Gu et al [41] presented Sleep Hunter, a mobile service that detects the transition between sleep stages for monitoring sleep quality and intelligent wakefulness. The smartphone was placed next to the participant's pillow. Using sensors integrated in smartphones, Sleep Hunter integrates body movements, acoustic events, environmental lighting conditions, sleep duration, and personal factors using a statistical model: linear-chain conditional random field (CRF) [117] for sleep stage detection. It argued that, compared with the hidden Markov model [118], CRFs are more relevant for sequences that have long interdependencies and may therefore perform better in this application. On the basis of the duration of each sleep stage, Sleep Hunter also provides a report on sleep quality and a smart call service for users. In this work [41], commercial product Zeo [119] was adopted as the reference device. One study [120] indicated that the quality of sleep is actually determined by the distribution of the different stages of sleep rather than the length of sleep during the night. This work distinguished sleep stages between wakefulness, light sleep, deep sleep, and REM. The sleep quality score is then calculated based on the duration of each sleep stage. The detection accuracy of the Sleep Hunter proposed in this work [41] was $64.55 \%$.

Krishna et al [121] proposed SleepSensei, an automated sleep quality monitor that estimates the sleep duration for the user. It uses (1) the built-in web camera and microphone of a personal computer connected to a power source, and custom software to collect environmental features and (2) the accelerometer sensor of a smartphone to detect body movements. Smartphones are placed close to the user (next to the pillow). In this system, the user can be in 1 of 2 sleep states: deep sleep or light sleep. The user's sleep state (sound or light) is determined solely on the basis of the variance of the user's body movements during sleep. Environmental features such as light intensity, ambient noise, temperature, and humidity have been entered by using custom software.

Temperature, ambient sound (noise and music), and light conditions have been found to be strong indicators of the user's environment that clearly affect sleep [122]. The system proposed a regression model consisting of linear regression and SVM regression. The regression model estimates the share of each time slot (30-min window) that contributes to the completion of a user's sleep quota (the total duration of sleep a user needs to obtain satisfactory sleep). The ground truth of this system comes from the data provided by users on sleep quality by answering the question: was the sleep fulfilling? It uses SVM and naive Bayes models as classifiers. By comparing the results of each classifier with 2 and 4 times cross-validation, the SVM model with 2 times cross validations has the best results and has an average accuracy of $79.84 \%$.

\section{Contact Methods}

\section{Distributed Sensor System on the Body}

Velicu et al [68] proposed a system based on an accelerometer and an ECG sensor for the classification of sleep phases (wakefulness, light sleep, deep sleep, and REM). The accelerometer was embedded into a wristband, but the position of the ECG sensor was not mentioned. It described the classification logic: (1) body movements become less intense and less frequent as we enter the deeper phases of sleep and (2) HR becomes more stable as sleep deepens. The Kushida algorithm-derived equation [69] was adopted in this system as a discriminator between wake and sleep using accelerometer data collected every minute, with a 9-min sliding time window, showing $69 \%$ agreement with the EEG sensor result. This work shows a part of the classification results for an experiment lasting 3 hour and $43 \mathrm{~min}$. However, the results have not been validated against PSG or any other reliable standard.

Kalkbrenner et al [70] presented the first step in the development of a sleep monitoring system. It includes the capabilities of capturing heartbeats, breathing, snoring, sleeping positions, and movements of 2 volunteers. In this system, a microphone was set up at the suprasternal notch to record breathing sounds and heart sounds. The heart signal is extracted by applying a bandpass filter from $15 \mathrm{~Hz}$ to $80 \mathrm{~Hz}$. Nakano [71] and Yadollahi [72] showed that placing a stethoscope such as a microphone in the suprasternal notch at night can detect sleep apnea. At the same time, an MPU6000 inertial measurement unit embedded in an abdominal belt worn by the patient determines the sleep position and movements. The data are transmitted wirelessly to the laptop via Bluetooth and processed, visualized, and stored using developed software. The validation of the proposed system by comparison with the gold standard was published in [73]. A total of 60 adult subjects were subjected to overnight diagnosis, and a PSG screening was included for validation of the proposed 
system. A total of 30 dimensions of features were extracted from data on breath, heartbeat, and movement. A linear discriminant (LD) classifier was used for automated sleep staging. The classifier achieved $86.9 \%$ accuracy and a kappa of 0.69 for sleep or wake classification, $76.3 \%$ accuracy and a kappa of 0.42 for Wake or REM or NREM classification, and $56.5 \%$ accuracy and a kappa of 0.36 for wake or REM or light sleep or deep sleep classification.

Lee et al [74] proposed smart patches and wearable bands (W-band) for recording biosignals during sleep. The system consists of 15 smart patches attached to the user's face to monitor multiple biosignals (EEG, ECG, EMG, and EOG). A total of 14 biosignal sensing ( $\mathrm{SN}$ ) patches to monitor biosignals, a network controller (NC) patch placed behind the ear to manage the whole system and used as a reference electrode for ECG, EEG, and EOG signals. All electrodes are implemented on a multilayered fabric patch based on the Planar Fashionable Circuit Board technology. The biosignals recorded by the $\mathrm{SN}$ patches were collected in the NC patch with an internal $20 \mathrm{~kb}$ SRAM via the W-band. When the memory is full, the recorded data are transmitted to an external device via an inductively coupled interface. The program displaying the data runs on an external PC so that the user can check the monitoring result after waking up. The performance of biosignal recording by this system has not been compared with a gold standard.

\section{Stand-Alone System With Several Sensors}

Shambroom et al [75] evaluated a wireless system for automatic collection and scoring of human sleep. This system uses dry silver-coated fabric sensors in the headband to collect electrophysiological signals from the forehead, which include contributions from the EEG and eye and frontal muscle movements. The resulting signal is transmitted to a base station using an ultra-low-power wireless protocol at $2.4 \mathrm{GHz}$. The system was compared with the PSG data scored by 2 technicians according to the $\mathrm{R} \& \mathrm{~K}$ criteria. A reduced set of sleep stage classifications was adopted, including awake, REM, light sleep (combined stages N1 and N2), and deep sleep (combined Stages N3 and N4) [17]. A total of 26 healthy adults were subjected to simultaneous sleep measurements using this system and the PSG. The agreement was $62 \%$ and $56 \%$, respectively, with regard to PSG1 (PSG recording scored by technician 1) and PSG2 (PSG recording scored by technician 2). The mean (SD) entire night sleep stage agreement for the 26 subjects was $75.9 \%$ (7.0\%) for this system versus PSG1 (PSG recording scored by technician 1), $74.7 \%$ (8.5\%) for this system versus PSG2 (PSG recording scored by technician 2 ), and $81.2 \%$ (7.4\%) for this system versus PSGC (PSG recording scored consistently by 2 technicians).

Suzuki et al [76] described a wristwatch-shaped wearable sleep monitoring system for home use. The sensor incorporates a photoelectric pulse wave sensor and a 3-axis accelerometer to measure pulse waves and accelerations on a user's wrist and stores the computed pulse intervals (PPIs) and amount of activity in a flash memory (4 MB). It uses the Cole algorithm to identify wake or sleep from the amount of activity data [77]. The system compared the estimation result with the PSG results. Fast Fourier transform (FFT) is performed to obtain the heart rate spectrum.
In the frequency domain, the integral value of the power from $0.04 \mathrm{~Hz}$ to $0.15 \mathrm{~Hz}$ is called LF (low frequency), which shows both sympathetic and parasympathetic nervous activities. The integral value of the power from $0.15 \mathrm{~Hz}$ to $0.4 \mathrm{~Hz}$ is called $\mathrm{HF}$ (high frequency), which shows parasympathetic nervous activity. The balance between sympathetic and parasympathetic nervous activity is related to sleep stages. According to the study by Baharav et al [78], there is a decrease in LF during sleep, with minimal values during non-REM slow-wave sleep, that is, deep sleep, and high levels similar to those of wakefulness during REM.

The HF increased with the onset of sleep, reaching maximal values during slow-wave sleep, and behaved as a mirror image of LF, as shown in Figure 6. The correlation between HF, LF of PPI, and sleep stages is summarized in Table 5.

The sympathetic predominance that characterizes wakefulness decreases during non-REM sleep, is minimal during slow wave sleep, and approaches average levels of wakefulness during REM sleep. Autonomic balance shifts to parasympathetic predominance during slow-wave sleep. To classify sleep stages from the LF and HF data sets, the k-means clustering method is adopted. It defines the coincidence ratio as a moving average sleep stage correlation coefficient (20-min window) between the stages estimated by this method and those estimated by the PSG. A mean coincidence ratio of 0.735 (SD 0.052) was obtained for the classification of the SWS, REM, non-REM, and wake stages.

Beattie et al [108] estimated sleep stages using a wrist-worn device that measured movements using a 3D accelerometer and an optical pulse photoplethysmograph, which provided data on movement, breathing, and heart rate variability. Overnight recordings were obtained from 60 adult participants wearing these devices on their left and right wrists, simultaneously with a type III home sleep testing device (Embletta MPR) that included EEG channels for sleep staging. The reference Embletta recordings were scored for sleep stages using the AASM guidelines [79], which labeled sleep stages as awake, light (N1 or N2), deep (N3), and REM over 30 second epoch level. Motion-based features include the number of activities over 30 second, the magnitude of rotation (using the 3D accelerometer to combine the maximum-minimum of each axis), the time from the last significant movement, and the time to the next significant movement. It extracted heart rate features such as HF power $(0.15-0.4 \mathrm{~Hz}), \mathrm{LF}$ power $(0.04-0.15 \mathrm{~Hz})$, very low frequency (VLF) power (0.01-0.04 Hz), root mean square of the successive differences, pNN50 (proportion of the number of pairs of successive RR intervals (the interval between $R$ waves of ECG, that is, the time between heart beats) that differ by more than $50 \mathrm{msec}$ divided by the total number of RR intervals), delta RR (intervals between beats), and mean heart rate.

The spectral features of the estimated breathing rate on a $1 \mathrm{~s}$ basis such as HF power $(0.15-0.4 \mathrm{~Hz}), \mathrm{LF}$ power $(0.04-0.15$ $\mathrm{Hz})$, and VLF power $(0.015-0.04 \mathrm{~Hz})$ were formed. This system used the Scikit library to explore different types of classifiers: LD classifiers, quadratic discriminant classifiers, RFs, and SVM approaches. The LD mode seems to work slightly better than 
the others, so it was chosen as the final model. On the basis of a single validation, the overall accuracy per epoch of the automated algorithm was $69 \%$, with a Cohen kappa of 0.52 (SD $0.14)$.

Figure 6. Illustration of HF and LF from PPI [97].

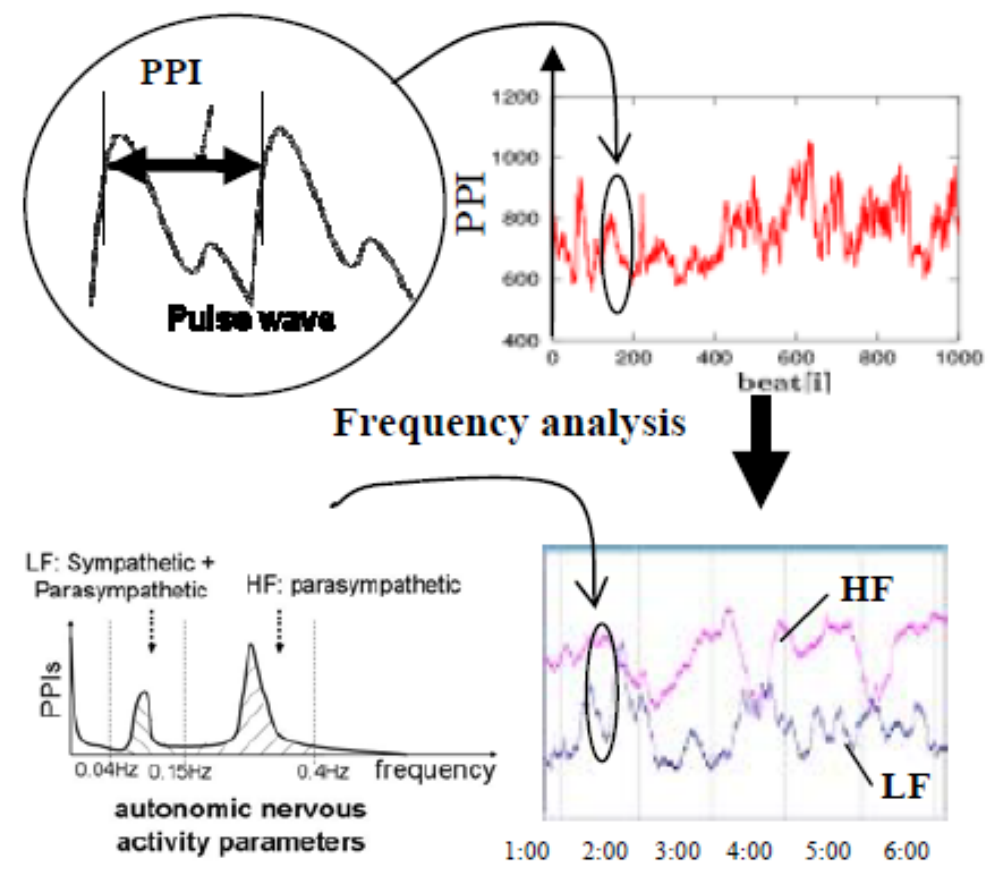

Table 5. Correlation between high frequency and low frequency from pulse-to-pulse intervals and sleep stages.

\begin{tabular}{llll}
\hline Frequency bands & Sleep onset & Slow wave sleep & Wakefulness \\
\hline $\mathrm{HF}^{\mathrm{a}}$ & Increase & Maximal & Low level \\
$\mathrm{LF}^{\mathrm{b}}$ & Decrease & Minimal & high level
\end{tabular}

${ }^{\mathrm{a}} \mathrm{HF}$ : high frequency.

${ }^{\mathrm{b}} \mathrm{LF}$ : low frequency.

\section{Only One Sensor Attached to One Site of Body}

Tataraidze et al [80] presented an algorithm for detecting wakefulness, REM, and non-REM sleep based on a set of 33 features extracted from the respiratory inductive plethysmography signal captured by the PSG thoracic belt. The features extracted include the logarithm of power in different frequency ranges, time and frequency domain features, motion, breathing, and volume-based features. A bagging classifier was used in the experiments and a heuristic algorithm was applied to increase the performance of the classification. Compared with the PSG gold standard, an accuracy of 80.38 (SD 8.32\%) and a Cohen kappa of 0.65 (SD 0.13) were obtained with the classifier.

\section{Commercial Products}

Given the various shortcomings of PSG, such as its invasiveness, high cost, and one-night monitoring, the industry has shown great enthusiasm for the development of commercial sleep monitoring products with the advantages of being portable, noninvasive, and suitable for long-term monitoring. Commercial products used for home sleep monitoring are currently available for direct purchases on the market. Some of the most popular and representative products are briefly introduced below.
Zeo [119] is a headband based on a true lightweight EEG brainwave pod monitor. It can provide a classification of sleep stages into awake, light (stages 1 and 2 combined), deep (stages 3 and 4 combined), and REM sleep. The Companion for Zeo smartphone app was developed for data collection. A validation study has been published [75]. Compared with the PSG, the epoch-to-epoch concordance of light, deep, and REM sleep is greater than $74 \%$.

Up (Jawbone) [81] is a soft rubber wristband. In terms of sleep monitoring, it provides total sleep duration, time to fall asleep, and the number of nighttime awakenings. It also interacts with smartphone apps. To date, there have been no validation studies.

Fitbit [82] is also a wristband product. Its sleep monitoring algorithm classifies night sleep into awake, light sleep, deep sleep, and REM based on wrist movements and heart rate data. It also provides total sleep duration, sleep starting time, and end time. The publication [83] evaluates the performance of the Fitbit against the PSG. It showed a sensitivity of 0.96 (sleep detection accuracy), a specificity of 0.61 (wakefulness detection accuracy), an accuracy of 0.81 for the detection of $\mathrm{N} 1+\mathrm{N} 2$ sleep (light sleep), an accuracy of 0.49 for the detection of N3 sleep (deep sleep), and an accuracy of 0.74 for the detection of REM sleep. 
RestOn [84] is a thin belt. It uses a single click of the magnetic cover to fix the device on the bedsheet; the position corresponds to the user's chest. RestOn can measure heart rate and respiratory rate in real time. Medical-grade sensors that are 2-foot long are embedded into a thin belt less than a length of $2 \mathrm{~mm}$. The device can provide sleep time, actual sleep time, and sleep stages including awake, light, medium, and deep sleep. Its smart alarm can wake the user during the lightest sleep time.

The Sleep Dot [85] measures sleep cycles and body movements by simply attaching it to the upper corner of the pillow. It can play music to help the user fall asleep. Soothing sounds and music are adopted as alarm tones to wake the user more naturally during the lightest sleep. This product works with a smartphone app and generates a sleep report that can be shared with family and friends.

Withings Aura [86] is a bedside device with a white cloth sleep sensor placed under the mattress, aligned in position with the user's chest. It is recommended that the 11-inch high bedside device be placed at least $1 \mathrm{~m}$ from the bed. The bedside device measures environmental parameters such as temperature, light, and noise. The white cloth sleep sensor indicates the time to sleep, number of awakenings during the night, duration of light sleep or deep sleep or REM sleep, and percentage of sleep goal achieved.

\section{Our Proposition of Sleep Monitoring System}

The LAAS-CNRS (Laboratory for Analysis and Architecture of Systems-French National Centre for Scientific Research) has been developing systems for monitoring people since 1990 $[87,88]$. This mainly includes research on health monitoring for older adults and frail people at home based on a wireless local body area network (WLBAN) [89-91]. On the basis of the techniques and experiences of studying the WLBAN monitoring system for many years, our laboratory has started research on sleep monitoring. The objective is to perform continuous and long-term sleep monitoring at home, focusing on the variance of sleep conditions night by night and monitoring indicator deviations after each night. The first week's sleep is considered the reference nights and is used for comparison of the following nights. When an abnormal condition is detected, the user is warned via a specific visual interface (graph or other) on a computer, tablet, or smartphone.

Many indicators may be relevant for monitoring sleep conditions, such as the following:

1. Distribution of sleep stages during the night.
2. Number of wrist activities.

3. Amount of leg activity during sleep (this is also the main indicator of Restless Legs Syndrome [RLS]).

4. Body turnover time.

5. Onset of snoring. If so, the duration and number of apneas.

The contribution here is to propose the following indexes:

- Change in apnea behavior.

- Sleep phase deviation.

- Leg movement.

- Heart rate and blood oxygen saturation.

- $\quad$ Finger, big toe, and chest temperature.

- Temperature and brightness of the environment.

Thresholds on these indexes could trigger alerts to the doctor. It is also possible to correlate these indices to provide an overall index of sleep quality.

The current research at the LAAS-CNRS on sleep monitoring is shown in Figure 7. The developed system consists of a local network integrating sensors embedded on the person, and these sensors communicate using Bluetooth to a data concentrator (Master). The master communicates via an Android app with the person itself. The master transmits the data via the LoRa technology to a gateway that takes care of sending the data to a database that can be remotely consulted by the physician.

Using this system, we collect a hypnogram based on wrist movement data using the clustering algorithm and to monitor the restless leg syndrome using leg movement data and to detect symptoms such as snoring using sound data.

We proposed threshold-based and k-means clustering based methods to process acceleration data from the nondominant wrist. The threshold-based method uses 3 thresholds to achieve falling asleep or waking up detection and 4-sleep stages classification (awake, light sleep, deep sleep, and REM). The k-means clustering-based method performs 5-iteration of $\mathrm{k}$-means clustering for epochs between falling asleep and waking up to also achieve a 4-sleep stage classification (awake, light sleep, deep sleep and REM). The epochs between falling asleep and waking up are determined by falling asleep or waking up detection from the threshold-based method. Furthermore, a method for calculating sleep scores for a night's sleep is also proposed in our system. The calculation of the sleep score was based on the sleep duration and the duration of each sleep stage. With tests carried out on 5 volunteers, all the methods we propose give promising results. The related article will be submitted soon. 
Figure 7. Sleep monitoring system ongoing research at LAAS (Laboratory for Analysis and Architecture of Systems).

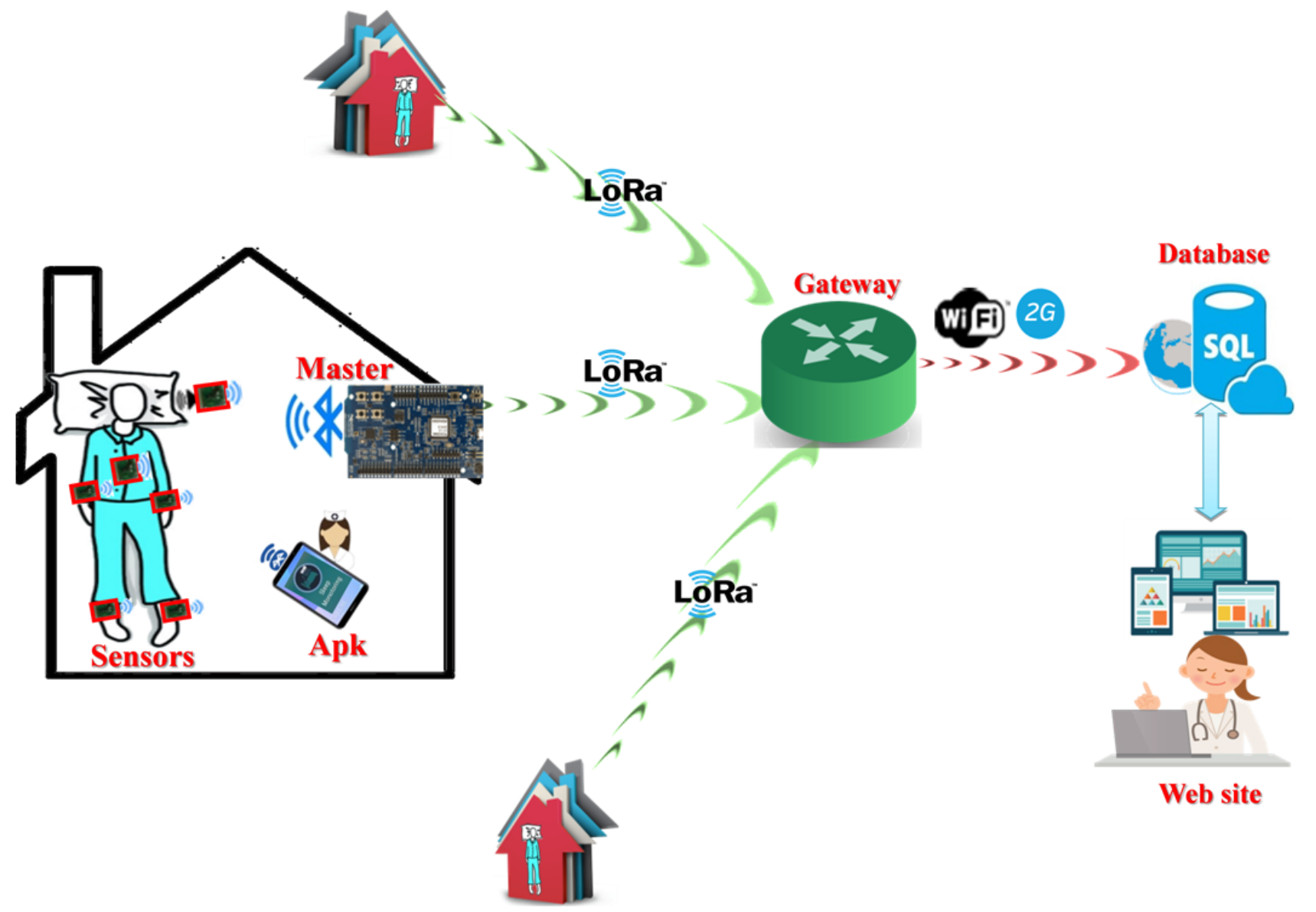

\section{Conclusions}

The objective of this paper is to provide an overview of the current state and future prospects of research and development of sleep monitoring system s. Observation and sleep monitoring is a very important medical issue for the possible consequences on life behavior. The gold standard used is the PSG technique, which is an intrusive method that can only be used in a clinical setting. In addition, several studies have focused on the development of methods and strategies for lighter and longitudinal monitoring. sleep monitoring systems have been proposed but they raise questions about the acceptance of the wearing of these devices by users, socioeconomic aspects, privacy, and impact on society, but also about the performance of the proposed algorithmic processing. This document deals with these issues and the different solutions reported in the literature and available on the market. The sleep monitoring system features a broad and heterogeneous range of devices, WSN standards, apps, and involve the efforts of numerous researchers, developers, and users. Owing to its interdisciplinary nature, a number of apps related to sleep monitoring integrate biomedical engineering and medical informatics. Other knowledge in the fields of medicine, social sciences, psychology, economics, ethics, and law must be taken into account and integrated into the development and deployment of wearable health care systems. Most systems are still in their prototype stages, and developers have not yet faced deployment issues. Information technology and electronics are mature fields and can provide viable, disposable, and affordable wearable systems.
Systematic evaluations of the effectiveness and efficiency of sleep monitoring system are considered crucial to ensure potential user acceptance. Sleep monitoring is important for individuals and clinicians. Beyond the interest in healthy lifestyle and clinical diagnosis, sleep monitoring may also be important in reducing fatigue-related workplace injuries, particularly for shift workers. However, this type of monitoring will only be practical if systems with proven reliability and validity are in place. Consumers and patients will have the opportunity to take part in the revolution in personal health data. Increasingly powerful and convenient wearable technologies will be able to provide rich health information, but it is not clear that this will translate into workable health decisions. The democratization of devices previously reserved for doctors should improve access to health data and overall awareness of personal health. It is important that such information is properly communicated and understood by consumers. More complex integrated sensor technologies, detection, and analytical algorithms are likely to be developed in the coming years. Other wearable diagnostic tools for consumers, or even implantable devices and nanotechnologies, are currently under development. Products exist that can integrate sensors into clothing. Ideally, these technologies will empower consumers and patients and promote preventive medicine. The most important challenges are the development of nonintrusive hardware implementation, smart signal processing, data analysis and interpretation, communication standards interoperability, electronic component efficiency, energy self-sufficiency, and long-term monitoring. 


\section{Conflicts of Interest}

None declared.

\section{Multimedia Appendix 1}

Hardware implementation in different works.

[DOCX File, 24 KB-Multimedia Appendix 1]

\section{References}

1. van de Straat V, Buffel V, Bracke P. Medicalization of sleep problems in an aging population: a longitudinal cross-national study of medication use for sleep problems in older European adults. J Aging Health 2018 Jun;30(5):816-838. [doi: 10.1177/0898264317696775] [Medline: $\underline{28553808]}$

2. Bao YP, Han Y, Ma J, Wang RJ, Shi L, Wang TY, et al. Cooccurrence and bidirectional prediction of sleep disturbances and depression in older adults: meta-analysis and systematic review. Neurosci Biobehav Rev 2017 Apr;75:257-273. [doi: 10.1016/j.neubiorev.2017.01.032] [Medline: 28179129]

3. Reutrakul S, van Cauter E. Sleep influences on obesity, insulin resistance, and risk of type 2 diabetes. Metabolism 2018 Jul;84:56-66. [doi: 10.1016/j.metabol.2018.02.010] [Medline: 29510179]

4. Tobaldini E, Costantino G, Solbiati M, Cogliati C, Kara T, Nobili L, et al. Sleep, sleep deprivation, autonomic nervous system and cardiovascular diseases. Neurosci Biobehav Rev 2017 Mar;74(Pt B):321-329. [doi:

10.1016/j.neubiorev.2016.07.004] [Medline: 27397854]

5. Suzuki H, Savitz J, Kent Teague T, Gandhapudi SK, Tan C, Misaki M, et al. Altered populations of natural killer cells, cytotoxic T lymphocytes, and regulatory $\mathrm{T}$ cells in major depressive disorder: association with sleep disturbance. Brain Behav Immun 2017 Nov;66:193-200 [FREE Full text] [doi: 10.1016/j.bbi.2017.06.011] [Medline: 28645775]

6. Lewis PA, Knoblich G, Poe G. How memory replay in sleep boosts creative problem-solving. Trends Cogn Sci 2018 Jun;22(6):491-503. [doi: 10.1016/j.tics.2018.03.009] [Medline: 29776467]

7. Huber R, Born J. Sleep, synaptic connectivity, and hippocampal memory during early development. Trends Cogn Sci 2014 Mar;18(3):141-152. [doi: 10.1016/j.tics.2013.12.005] [Medline: 24462334]

8. Scullin MK, Bliwise DL. Sleep, cognition, and normal aging: integrating a half century of multidisciplinary research. Perspect Psychol Sci 2015 Jan;10(1):97-137 [FREE Full text] [doi: 10.1177/1745691614556680] [Medline: 25620997]

9. Gami AS, Howard DE, Olson EJ, Somers VK. Day-night pattern of sudden death in obstructive sleep apnea. N Engl J Med 2005 Mar 24;352(12):1206-1214. [doi: 10.1056/NEJMoa041832] [Medline: 15788497]

10. Stranges S, Tigbe W, Gómez-Olivé FX, Thorogood M, Kandala NB. Sleep problems: an emerging global epidemic? Findings from the INDEPTH WHO-SAGE study among more than 40,000 older adults from 8 countries across Africa and Asia. Sleep 2012 Aug 1;35(8):1173-1181 [FREE Full text] [doi: 10.5665/sleep.2012] [Medline: 22851813]

11. Dregan A, Armstrong D. Cross-country variation in sleep disturbance among working and older age groups: an analysis based on the European social survey. Int Psychogeriatr 2011 Nov;23(9):1413-1420. [doi: 10.1017/S1041610211000664] [Medline: 21554795]

12. Sutton DA, Moldofsky H, Badley EM. Insomnia and health problems in Canadians. Sleep 2001 Sep 15;24(6):665-670. [doi: 10.1093/sleep/24.6.665] [Medline: 11560179 ]

13. Kessler RC, Berglund PA, Coulouvrat C, Hajak G, Roth T, Shahly V, et al. Insomnia and the performance of US workers: results from the America insomnia survey. Sleep 2011 Sep 1;34(9):1161-1171 [FREE Full text] [doi: 10.5665/SLEEP.1230] [Medline: 21886353]

14. Uehli K, Mehta AJ, Miedinger D, Hug K, Schindler C, Holsboer-Trachsler E, et al. Sleep problems and work injuries: a systematic review and meta-analysis. Sleep Med Rev 2014 Feb;18(1):61-73 [FREE Full text] [doi: 10.1016/j.smrv.2013.01.004] [Medline: 23702220]

15. Filip I, Tidman M, Saheba N, Bennett H, Wick B, Rouse N, et al. Public health burden of sleep disorders: underreported problem. J Public Health 2016 Dec 6;25(3):243-248 [FREE Full text] [doi: 10.1007/s10389-016-0781-0]

16. Hafner M, Stepanek M, Taylor J, Troxel WM, van Stolk C. Why sleep matters-the economic costs of insufficient sleep: a cross-country comparative analysis. Rand Health Q 2017 Jan;6(4):11 [FREE Full text] [Medline: 28983434]

17. Allan Hobson J. A manual of standardized terminology, techniques and scoring system for sleep stages of human subjects. Clin Neurophysiol 1969 Jun;26(6):644. [doi: 10.1016/0013-4694(69)90021-2]

18. Iber C, Ancoli-Israel S, Chesson A, Quan S. The AASM Manual for the Scoring of Sleep and Associated Events. American Academy of Sleep Medicine. 2007. URL: https://aasm.org/clinical-resources/scoring-manual/ [accessed 2020-08-13]

19. Moser D, Anderer P, Gruber G, Parapatics S, Loretz E, Boeck M, et al. Sleep classification according to AASM and Rechtschaffen \& Kales: effects on sleep scoring parameters. Sleep 2009 Feb;32(2):139-149 [FREE Full text] [doi: 10.1093/sleep/32.2.139] [Medline: 19238800]

20. Himanen S, Hasan J. Limitations of Rechtschaffen and Kales. Sleep Med Rev 2000 Apr;4(2):149-167. [doi: $\underline{10.1053 / \text { smrv.1999.0086] [Medline: } 12531164 \text { ] }}$ 
21. Fino E, Mazzetti M. Monitoring healthy and disturbed sleep through smartphone applications: a review of experimental evidence. Sleep Breath 2019 Mar;23(1):13-24. [doi: 10.1007/s11325-018-1661-3] [Medline: 29687190]

22. Westerlund A, Lagerros YT, Kecklund G, Axelsson J, Åkerstedt T. Relationships between questionnaire ratings of sleep quality and polysomnography in healthy adults. Behav Sleep Med 2016;14(2):185-199. [doi: 10.1080/15402002.2014.974181] [Medline: 25384098]

23. Sateia MJ. International classification of sleep disorders-third edition: highlights and modifications. Chest 2014 Nov;146(5):1387-1394. [doi: 10.1378/chest.14-0970] [Medline: 25367475]

24. Ohayon MM. Epidemiology of insomnia: what we know and what we still need to learn. Sleep Med Rev 2002 Apr;6(2):97-111. [doi: 10.1053/smrv.2002.0186] [Medline: 12531146]

25. Avc1 C, Akbaş A. Sleep apnea classification based on respiration signals by using ensemble methods. Bio-Med Mater Eng 2015 Aug 17;26(s1):S1703-S1710. [doi: 10.3233/bme-151470]

26. Hou L, Xie S, Kai S. Detection of OSAHS Using Only Time-Domain Property of Snoring Signal. In: International Conference on Multimedia Technology. 2011 Presented at: ICMT'11; Jul 26-28, 2011; Hangzhou, China. [doi: $10.1109 /$ icmt.2011.6002183]

27. Karunajeewa AS, Abeyratne UR, Hukins C. Multi-feature snore sound analysis in obstructive sleep apnea-hypopnea syndrome. Physiol Meas 2011 Jan;32(1):83-97. [doi: 10.1088/0967-3334/32/1/006] [Medline: 21119221]

28. Solà-Soler J, Fiz JA, Morera J, Jané R. Multiclass classification of subjects with sleep apnoea-hypopnoea syndrome through snoring analysis. Med Eng Phys 2012 Nov;34(9):1213-1220. [doi: 10.1016/j.medengphy.2011.12.008] [Medline: 22226588]

29. Walters AS, LeBrocq C, Dhar A, Hening W, Rosen R, Allen TP, International Restless Legs Syndrome Study Group. Validation of the international restless legs syndrome study group rating scale for restless legs syndrome. Sleep Med 2003 Mar;4(2):121-132. [doi: 10.1016/s1389-9457(02)00258-7] [Medline: 14592342]

30. Plante DT. Leg actigraphy to quantify periodic limb movements of sleep: a systematic review and meta-analysis. Sleep Med Rev 2014 Oct;18(5):425-434 [FRE Full text] [doi: 10.1016/j.smrv.2014.02.004] [Medline: 24726711]

31. Terrill PI, Leong M, Barton K. Measuring Leg Movements During Sleep Using Accelerometry: Comparison With EMG and Piezo-Electric Scored Events. In: 35th Annual International Conference of the IEEE Engineering in Medicine and Biology Society. 2013 Presented at: EMBC'13; July 3-7, 2013; Osaka, Japan p. -6865. [doi: 10.1109/embc.2013.6611134]

32. Madhushri P, Ahmed B, Penzel T. Periodic Leg Movement (PLM) Monitoring Using a Distributed Body Sensor Network. In: 37th Annual International Conference of the IEEE Engineering in Medicine and Biology Society. 2015 Presented at: EMBC'15; August 25-29, 2015; Milan, Italy. [doi: 10.1109/embc.2015.7318738]

33. Ohayon MM, Roth T. Prevalence of restless legs syndrome and periodic limb movement disorder in the general population. J Psychosom Res 2002 Jul;53(1):547-554. [doi: 10.1016/s0022-3999(02)00443-9] [Medline: 12127170]

34. Montplaisir J, Allen RP, Arthur W. Restless Legs Syndrome and Periodic Limb Movements During Sleep. Italian Ministry of Health. 2010. URL: https://moh-it.pure.elsevier.com/en/publications/ restless-legs-syndrome-and-periodic-limb-movements-during-sleep-2 [accessed 2020-08-13]

35. Zucconi M, Ferini-Strambi L. NREM parasomnias: arousal disorders and differentiation from nocturnal frontal lobe epilepsy. Clin Neurophysiol 2000 Sep;111(Suppl 2):S129-S135. [doi: 10.1016/s1388-2457(00)00413-2] [Medline: 10996566]

36. Ferini-Strambi L, Zucconi M. REM sleep behavior disorder. Clin Neurophysiol 2000 Sep;111:S136-S140. [doi: 10.1016/s1388-2457(00)00414-4]

37. Gitanjali B. Establishing a polysomnography laboratory in India: problems and pitfalls. Sleep 1998 Jun 15;21(4):331-332. [doi: 10.1093/sleep/21.4.331] [Medline: 9646376]

38. Guettari T, Istrate D, Boudy J, Benkelfat B, Fumel B, Daviet J. Design and first evaluation of a sleep characterization monitoring system using a remote contactless sensor. IEEE J Biomed Health Inform 2017 Nov;21(6):1511-1523. [doi: 10.1109/jbhi.2016.2639823]

39. Liu J, Chen Y, Wang Y, Chen X, Cheng J, Yang J. Monitoring vital signs and postures during sleep using WiFi signals. IEEE Internet Things J 2018 Jun;5(3):2071-2084. [doi: 10.1109/jiot.2018.2822818]

40. Roomkham S, Lovell D, Cheung J, Perrin D. Promises and challenges in the use of consumer-grade devices for sleep monitoring. IEEE Rev Biomed Eng 2018;11:53-67. [doi: 10.1109/RBME.2018.2811735] [Medline: 29993607]

41. Gu W, Shangguan L, Yang Z, Liu Y. Sleep hunter: towards fine grained sleep stage tracking with smartphones. IEEE Trans on Mobile Comput 2016 Jun 1;15(6):1514-1527. [doi: 10.1109/tmc.2015.2462812]

42. Barrón-González HG, Martínez-Espronceda M, Trigo JD, Led S, Serrano L. Proposal of a novel remote command and control configuration extension for interoperable personal health devices (PHD) based on ISO/IEEE11073 standard. Conf Proc IEEE Eng Med Biol Soc 2014;2014:6312-6315. [doi: 10.1109/EMBC.2014.6945072] [Medline: 25571440]

43. Arney D, Plourde J, Goldman JM. OpenICE medical device interoperability platform overview and requirement analysis. Biomed Tech (Berl) 2018 Feb 23;63(1):39-47. [doi: 10.1515/bmt-2017-0040] [Medline: 28734113]

44. McHill AW, Wright KP. Role of sleep and circadian disruption on energy expenditure and in metabolic predisposition to human obesity and metabolic disease. Obes Rev 2017 Feb;18(Suppl 1):15-24. [doi: 10.1111/obr.12503] [Medline: 28164449]

45. Lee SW, $\mathrm{Ng} \mathrm{KY,} \mathrm{Chin} \mathrm{WK.} \mathrm{The} \mathrm{impact} \mathrm{of} \mathrm{sleep} \mathrm{amount} \mathrm{and} \mathrm{sleep} \mathrm{quality} \mathrm{on} \mathrm{glycemic} \mathrm{control} \mathrm{in} \mathrm{type} 2$ diabetes: a systematic review and meta-analysis. Sleep Med Rev 2017 Feb;31:91-101. [doi: 10.1016/j.smrv.2016.02.001] [Medline: 26944909] 
46. Fuchs FD, Fuchs SC, Martinez D. Obstructive sleep apnea-Hypertension link: almost there? J Thorac Dis 2017 Oct;9(10):3537-3540 [FREE Full text] [doi: 10.21037/jtd.2017.08.162] [Medline: 29268335]

47. Hossain JL, Shapiro CM. The prevalence, cost implications, and management of sleep disorders: an overview. Sleep Breath 2002 Jun;6(2):85-102. [doi: 10.1007/s11325-002-0085-1] [Medline: 12075483]

48. Deng F, Dong J, Wang X, Fang Y, Liu Y, Yu Z, et al. Design and implementation of a noncontact sleep monitoring system using infrared cameras and motion sensor. IEEE Trans Instrum Meas 2018 Jul;67(7):1555-1563. [doi: 10.1109/tim.2017.2779358]

49. Okubo M, Imai Y, Ishikawa T. Development of Automatic Respiration Monitoring for Home-care Patients of Respiratory Diseases With Therapeutic AIDS. In: 4th European Conference of the International Federation for Medical and Biological Engineering. 2008 Presented at: ECIFMBE'08; November 23-27, 2008; Antwerp, Belgium. [doi: 10.1007/978-3-540-89208-3 267]

50. Coughlin JF. Aging \& Family Caregiving: Why Should Financial Services Care? Massachusetts Institute of Technology. 2006. URL: http://web.mit.edu/coughlin/Public/Publications/Coughlin\%20Caregiving\%20\&\%20Financial\%20Services. pdf [accessed 2020-08-13]

51. Barlow J, Bayer S, Curry R. Implementing complex innovations in fluid multi-stakeholder environments: experiences of 'telecare'. Technovation 2006 Mar;26(3):396-406. [doi: 10.1016/j.technovation.2005.06.010]

52. World Internet Usage and Population Statistics. Internet World Stats. 2020. URL: https://www.internetworldstats.com/stats. htm [accessed 2020-03-03]

53. Kelly JM, Strecker RE, Bianchi MT. Recent developments in home sleep-monitoring devices. ISRN Neurol 2012;2012:768794 [FREE Full text] [doi: 10.5402/2012/768794] [Medline: 23097718]

54. Coiera E. Four rules for the reinvention of health care. Br Med J 2004 May 15;328(7449):1197-1199 [FREE Full text] [doi: 10.1136/bmj.328.7449.1197] [Medline: 15142933]

55. de VN, Robert F, Penders J. Wireless Body Area Network for Sleep Staging. In: IEEE Biomedical Circuits and Systems Conference. 2007 Presented at: BIOCAS'07; November 27-30, 2007; Montreal, Quebec. [doi: 10.1109/biocas.2007.4463334]

56. Surantha N, Kusuma GP, Isa SM. Internet of Things for Sleep Quality Monitoring System: A Survey. In: 11th International Conference on Knowledge, Information and Creativity Support Systems. 2016 Presented at: KICSS'16; November 10-12, 2016; Yogyakarta, Indonesia. [doi: 10.1109/kicss.2016.7951426]

57. van de Water AT, Holmes A, Hurley DA. Objective measurements of sleep for non-laboratory settings as alternatives to polysomnography--a systematic review. J Sleep Res 2011 Mar;20(1 Pt 2):183-200 [FREE Full text] [doi:

10.1111/j.1365-2869.2009.00814.x] [Medline: 20374444]

58. Schomer DL, de Silva HL. Niedermeyer's Electroencephalography: Basic Principles, Clinical Applications, and Related Fields. New York, USA: Lippincott Williams \& Wilkins; 2005.

59. Chokroverty S. Atlas of Sleep Medicine. New York, USA: CRC Press; 2010.

60. Khalighi S, Sousa T, Pires G, Nunes U. Automatic sleep staging: a computer assisted approach for optimal combination of features and polysomnographic channels. Expert Systems with Applications 2013 Dec;40(17):7046-7059. [doi: 10.1016/j.eswa.2013.06.023]

61. Vaughn B, Quint S, Messenheimer J, Robertson K. Heart period variability in sleep. Clin Neurophysiol 1995 Mar;94(3):155-162. [doi: 10.1016/0013-4694(94)00270-u]

62. Townsend RE, Johnson LC, Naitoh P, Muzet AG. Heart rate preceding motility in sleep. Psychophysiology 1975 Mar;12(2):217-219. [doi: 10.1111/j.1469-8986.1975.tb01280.x] [Medline: 1135356]

63. Wu T, Wu F, Redoute J, Yuce MR. An autonomous wireless body area network implementation towards IoT connected healthcare applications. IEEE Access 2017;5:11413-11422. [doi: 10.1109/access.2017.2716344]

64. Rathee D, Rangi S, Chakarvarti SK, Singh VR. Recent trends in wireless body area network (WBAN) research and cognition based adaptive WBAN architecture for healthcare. Health Technol 2014 May 24;4(3):239-244. [doi: 10.1007/s12553-014-0083-x]

65. Milici S, Lazaro A, Villarino R, Girbau D, Magnarosa M. Wireless wearable magnetometer-based sensor for sleep quality monitoring. IEEE Sensors J 2018 Mar 1;18(5):2145-2152. [doi: 10.1109/jsen.2018.2791400]

66. Younes M, Soiferman M, Thompson W, Giannouli E. Performance of a new portable wireless sleep monitor. J Clin Sleep Med 2017 Feb 15;13(2):245-258 [FREE Full text] [doi: 10.5664/jcsm.6456] [Medline: 27784419]

67. Finan PH, Richards JM, Gamaldo CE, Han D, Leoutsakos JM, Salas R, et al. Validation of a wireless, self-application, ambulatory electroencephalographic sleep monitoring device in healthy volunteers. J Clin Sleep Med 2016 Nov 15;12(11):1443-1451 [FREE Full text] [doi: 10.5664/jcsm.6262] [Medline: 27707438]

68. Velicu OR, Madrid NM, Seepold R. Experimental Sleep Phases Monitoring. In: International Conference on Biomedical and Health Informatics. 2016 Presented at: BHI'16; February 24-27, 2016; Las Vegas, NV, USA. [doi: 10.1109/bhi.2016.7455976]

69. Kushida CA, Chang A, Gadkary C, Guilleminault C, Carrillo O, Dement WC. Comparison of actigraphic, polysomnographic, and subjective assessment of sleep parameters in sleep-disordered patients. Sleep Med 2001 Sep;2(5):389-396. [doi: 10.1016/s1389-9457(00)00098-8] [Medline: 14592388] 
70. Kalkbrenner C, Eichenlaub M, Brucher R. Development of a new homecare sleep monitor using body sounds and motion tracking. Curr Dir Biomed Eng 2015;1(1):30-33. [doi: 10.1515/cdbme-2015-0008]

71. Nakano H, Hayashi M, Ohshima E, Nishikata N, Shinohara T. Validation of a new system of tracheal sound analysis for the diagnosis of sleep apnea-hypopnea syndrome. Sleep 2004 Aug 1;27(5):951-957. [doi: 10.1093/sleep/27.5.951] [Medline: 15453554]

72. Yadollahi A, Giannouli E, Moussavi Z. Sleep apnea monitoring and diagnosis based on pulse oximetry and tracheal sound signals. Med Biol Eng Comput 2010 Nov;48(11):1087-1097. [doi: 10.1007/s11517-010-0674-2] [Medline: 20734154]

73. Kalkbrenner C, Brucher R, Kesztyüs T, Eichenlaub M, Rottbauer W, Scharnbeck D. Automated sleep stage classification based on tracheal body sound and actigraphy. Ger Med Sci 2019;17:Doc02 [FREE Full text] [doi: 10.3205/000268] [Medline: 30996721]

74. Lee S, Yan L, Roh T. The Smart Patches and Wearable Band (W-Band) for Comfortable Sleep Monitoring System. In: Annual International Conference of the IEEE Engineering in Medicine and Biology Society. 2011 Presented at: EMBC'11; August 30- September 3, 2011; Boston, USA. [doi: 10.1109/iembs.2011.6091741]

75. Shambroom JR, Fábregas SE, Johnstone J. Validation of an automated wireless system to monitor sleep in healthy adults. J Sleep Res 2012 Apr;21(2):221-230 [FREE Full text] [doi: 10.1111/j.1365-2869.2011.00944.x] [Medline: 21859438]

76. Suzuki T, Ouchi K, Kameyama K. Development of a Sleep Monitoring System with Wearable Vital Sensor for Home Use. Science and Technology Publications. 2009. URL: https://www.scitepress.org/papers/2009/17842/pdf/index.html [accessed 2020-08-13]

77. Cole RJ, Kripke DF, Gruen W, Mullaney DJ, Gillin JC. Automatic sleep/wake identification from wrist activity. Sleep 1992 Oct;15(5):461-469. [doi: 10.1093/sleep/15.5.461] [Medline: 1455130 ]

78. Baharav A, Kotagal S, Gibbons V, Rubin BK, Pratt G, Karin J, et al. Fluctuations in autonomic nervous activity during sleep displayed by power spectrum analysis of heart rate variability. Neurology 1995 Jun;45(6):1183-1187. [doi: 10.1212/wnl.45.6.1183] [Medline: 7783886]

79. Berry RB, Brooks R, Gamaldo CE, Harding SM, Lloyd RM. The AASM Manual for the Scoring of Sleep and Associated Events. American Academy of Sleep Medicine. 2015. URL: https://aasm.org/clinical-resources/scoring-manual/ [accessed 2020-08-13]

80. Tataraidze A, Anishchenko L, Korostovtseva L, Kooij BJ, Bochkarev M, Sviryaev Y. Sleep stage classification based on respiratory signal. Conf Proc IEEE Eng Med Biol Soc 2015;2015:358-361. [doi: 10.1109/EMBC.2015.7318373] [Medline: 26736273]

81. Jawbone Up: Fitness Tracker Review. Live Science. 2013. URL: https://www.livescience.com/40107-jawbone-up-review. html [accessed 2013-10-02]

82. FitBit. 2020 Aug 11. URL: https://www.fitbit.com/fr/store?utm source=\&utm medium=paidsearch\&gclid=Cj0KCQjwvDaBRCcARIsAI9sba9Dh12KY1zqUWJ1WLOZbS5BDheFt-ITkH3s-tE-652MtxsDMvoP3LgaAkgWEALw wcB\& dclid=CLevqriyutwCFcriGwodGHQL0Q [accessed 2020-08-11]

83. de Zambotti M, Goldstone A, Claudatos S, Colrain IM, Baker FC. A validation study of Fitbit charge 2 compared with polysomnography in adults. Chronobiol Int 2018 Apr;35(4):465-476. [doi: 10.1080/07420528.2017.1413578] [Medline: 29235907]

84. Sleepace. 2020. URL: http://www.sleepace.com/en/reston.html?category=reston [accessed 2020-08-11]

85. Sleep Dot B501. 2020. URL: http://www.sleepace.com/en/dot.html?category=dot [accessed 2020-08-11]

86. Withings Aura Sleep System. Sleep Trackers. 2020. URL: https://sleeptrackers.io/withings-aura/ [accessed 2020-08-11]

87. Chan M, Campo E, Estève D. Assessment of activity of elderly people using a home monitoring system. Int J Rehabil Res 2005 Mar;28(1):69-76. [doi: 10.1097/00004356-200503000-00010] [Medline: 15729100]

88. Campo E, Bonhomme S, Chan M. Remote Tracking Patients in Retirement Home Using Wireless Multisensor System. In: 12th IEEE International Conference on e-Health Networking, Applications and Services. 2010 Presented at: HEALTH'10; July 1-3, 2010; Lyon, France. [doi: 10.1109/health.2010.5556567]

89. Charlon Y, Bourennane W, Bettahar F, Campo E. Activity monitoring system for elderly in a context of smart home. IRBM 2013 Feb;34(1):60-63. [doi: 10.1016/j.irbm.2012.12.014]

90. Charlon Y, Campo E, Brulin D. Design and evaluation of a smart insole: application for continuous monitoring of frail people at home. Expert Syst Appl 2018 Apr;95:57-71. [doi: 10.1016/j.eswa.2017.11.024]

91. Charlon Y, Fourty N, Campo E. A telemetry system embedded in clothes for indoor localization and elderly health monitoring. Sensors (Basel) 2013 Sep 4;13(9):11728-11749 [FREE Full text] [doi: 10.3390/s130911728] [Medline: 24008286]

92. Saad WH, Khoo CW, Ab Rahman SI, Ibrahim MM, Saad NH. Development of sleep monitoring system for observing the effect of the room ambient toward the quality of sleep. In: IOP Conference Series: Materials Science and Engineering. 2017 Presented at: IOP'17; June 12-16, 2017; Prague, Czech Republic. [doi: 10.1088/1757-899x/210/1/012050]

93. Webb WB, Agnew HW. Sleep stage characteristics of long and short sleepers. Science 1970 Apr 3;168(3927):146-147. [doi: $10.1126 /$ science.168.3927.146] [Medline: 4313684]

94. Purves D, Augustine G, Fitzpatrick D. Physiological Changes in Sleep States. Second Edition. Washington, DC, USA: Neuroscience; 2001. 
95. 2015 Alaska Sleep Education Center. Improve Your Sleep. Improve Your Life. 2020 Aug 11. URL: http://www. alaskasleep.com/ [accessed 2020-08-11]

96. Suzuki T, Tanaka H, Minami S. Wearable Wireless Vital Monitoring Technology for Smart Health Care. In: 7th International Symposium on Medical Information and Communication Technology. 2013 Presented at: ISMICT'13; March 6-8, 2013; Tokyo, Japan. [doi: 10.1109/ismict.2013.6521687]

97. Chan AM, Selvaraj N, Ferdosi N. Wireless Patch Sensor for Remote Monitoring of Heart Rate, Respiration, Activity, and Falls. In: 35th Annual International Conference of the IEEE Engineering in Medicine and Biology Society. 2013 Presented at: EMBC'13; July 3-7, 2013; Osaka, Japan. [doi: 10.1109/embc.2013.6610948]

98. Sadek I, Seet E, Biswas J, Abdulrazak B, Mokhtari M. Nonintrusive vital signs monitoring for sleep apnea patients: a preliminary study. IEEE Access 2018;6:2506-2514. [doi: 10.1109/access.2017.2783939]

99. Sadek I, Biswas J, Abdulrazak B. Continuous and Unconstrained Vital Signs Monitoring With Ballistocardiogram Sensors in Headrest Position. In: International Conference on Biomedical \& Health Informatics. 2017 Presented at: BHI'17; February 16-19, 2017; Orlando, Florida, USA. [doi: 10.1109/bhi.2017.7897262]

100. Seba A, Istrate D, Guettari T, Ugon A, Pinna A, Garda P. Thermal-signature-based sleep analysis sensor. Informatics 2017 Oct 28;4(4):37. [doi: 10.3390/informatics4040037]

101. Sadek I, Biswas J, Yongwei Z. Sensor Data Quality Processing for Vital Signs With Opportunistic Ambient Sensing. In: 38th Annual International Conference of the IEEE Engineering in Medicine and Biology Society. 2016 Presented at: EMBC'16; August 16-20, 2016; Orlando, FL, USA. [doi: 10.1109/embc.2016.7591234]

102. Lee WK, Yoon H, Park KS. Smart ECG monitoring patch with built-in R-peak detection for long-term HRV analysis. Ann Biomed Eng 2016 Jul;44(7):2292-2301. [doi: 10.1007/s10439-015-1502-5] [Medline: 26558395]

103. Samy L, Huang M, Liu JJ, Xu W, Sarrafzadeh M. Unobtrusive sleep stage identification using a pressure-sensitive bed sheet. IEEE Sensors J 2014 Jul;14(7):2092-2101. [doi: 10.1109/jsen.2013.2293917]

104. Lee L, Lo Y, Yu J, Lee G, Ni Y, Chen N, et al. Snoring sounds predict obstruction sites and surgical response in patients with obstructive sleep apnea hypopnea syndrome. Sci Rep 2016 Jul 29;6:30629 [FREE Full text] [doi: 10.1038/srep30629] [Medline: 27471038]

105. Hou L, Wang C, Zhang C. Calculating AHI Combine Oximetery and Snore Sound. In: China Summit and International Conference on Signal and Information Processing. 2015 Presented at: ChinaSIP'15; July 12-15, 2015; Chengdu, China. [doi: 10.1109/chinasip.2015.7230364]

106. Emoto T, Abeyratne UR, Kawano K, Okada T, Jinnouchi O, Kawata I. Detection of sleep breathing sound based on artificial neural network analysis. Biomed Signal Proces 2018 Mar;41:81-89. [doi: 10.1016/j.bspc.2017.11.005]

107. Sadek I, Biswas J, Fook VF. Automatic Heart Rate Detection From FBG Sensors Using Sensor Fusion and Enhanced Empirical Mode Decomposition. In: International Symposium on Signal Processing and Information Technology. 2015 Presented at: ISSPIT'15; December 7-19, 2015; Abu Dhabi, United Arab Emirates. [doi: 10.1109/isspit.2015.7394358]

108. Beattie Z, Oyang Y, Statan A, Ghoreyshi A, Pantelopoulos A, Russell A, et al. Estimation of sleep stages in a healthy adult population from optical plethysmography and accelerometer signals. Physiol Meas 2017 Oct 31;38(11):1968-1979. [doi: 10.1088/1361-6579/aa9047] [Medline: 29087960]

109. Huang NE, Shen Z, Long SR, Wu MC, Shih HH, Zheng Q, et al. The empirical mode decomposition and the Hilbert spectrum for nonlinear and non-stationary time series analysis. Proc R Soc Lond A 1998 Mar 8;454(1971):903-995. [doi: 10.1098/rspa.1998.0193]

110. Charleston-Villalobos S, González-Camarena R, Chi-Lem G, Aljama-Corrales T. Crackle sounds analysis by empirical mode decomposition. Nonlinear and nonstationary signal analysis for distinction of crackles in lung sounds. IEEE Eng Med Biol Mag 2007;26(1):40-47. [doi: 10.1109/memb.2007.289120] [Medline: 17278771]

111. Balocchi R, Menicucci D, Santarcangelo E, Sebastiani L, Gemignani A, Ghelarducci B, et al. Deriving the respiratory sinus arrhythmia from the heartbeat time series using empirical mode decomposition. Chaos Soliton Fract 2004 Apr;20(1):171-177. [doi: 10.1016/s0960-0779(03)00441-7]

112. van Marken Lichtenbelt WD, Daanen HA, Wouters L, Fronczek R, Raymann RJ, Severens NM, et al. Evaluation of wireless determination of skin temperature using iButtons. Physiol Behav 2006 Jul 30;88(4-5):489-497. [doi: 10.1016/j.physbeh.2006.04.026] [Medline: 16797616 ]

113. van Someren EJ. Mechanisms and functions of coupling between sleep and temperature rhythms. Prog Brain Res 2006;153:309-324. [doi: 10.1016/S0079-6123(06)53018-3] [Medline: 16876583]

114. Kräuchi K, Deboer T. Body temperatures, sleep, and hibernation. Principl Pract Sleep Med 2011:323-334. [doi: 10.1016/b978-1-4160-6645-3.00028-1]

115. Keogh E, Lin J, Lee SH, Herle H. Finding the most unusual time series subsequence: algorithms and applications. Knowl Inf Syst 2006 Nov 23;11(1):1-27. [doi: 10.1007/s10115-006-0034-6]

116. van Hulle MM. Self-organizing maps. In: Handbook of Natural Computing. Berlin, Heidelberg: Springer; 2012:585-622.

117. Lafferty J, McCallum A, Pereira FC. Conditional Random Fields: Probabilistic Models for Segmenting and Labeling Sequence Data. University of Pennsylvania ScholarlyCommons. 2001. URL: https://repository.upenn.edu/cgi/viewcontent. cgi? article $=1162 \&$ context $=$ cis_papers [accessed 2020-08-13] 
118. Schuster-Böckler B, Bateman A. An introduction to hidden Markov models. Curr Protoc Bioinformatics 2007 Jun;Appendix 3:Appendix 3A. [doi: 10.1002/0471250953.bia03as18] [Medline: 18428778]

119. Zeo Sleep Manager Pro: Usage Tips. Gibson Research Corporation. 2016. URL: https://www.grc.com/zeo.htm [accessed 2016-05-10]

120. Carpenter JS, Andrykowski MA. Psychometric evaluation of the Pittsburgh sleep quality index. J Psychosom Res 1998 Jul;45(1):5-13. [doi: 10.1016/s0022-3999(97)00298-5] [Medline: 9720850]

121. Krishna A, Mallick M, Mitra B. SleepSensei: An Automated Sleep Quality Monitor and Sleep Duration Estimator. In: Proceedings of the First Workshop on IoT-enabled Healthcare and Wellness Technologies and Systems. 2016 Presented at: IoT of Health'16; June 25-30, 2016; Singapore,. [doi: 10.1145/2933566.2933570]

122. Kay M, Choe EK, Shepherd J. Lullaby: a Capture \& Access System for Understanding the Sleep Environment. In: Proceedings of the 2012 ACM Conference on Ubiquitous Computing. 2012 Presented at: UbiComp'12; September 5-8, 2012; Pittsburgh, USA. [doi: $\underline{10.1145 / 2370216.2370253}$ ]

\section{Abbreviations}

AASM: American Academy of Sleep Medicine

BCG: ballistocardiography

CRF: conditional random field

DAN: disorders of arousal from NREM

ECG: electrocardiography

EEG: electroencephalography

EMD: empirical mode decomposition

EMG: electromyography

EOG: electrooculography

FFT: fast Fourier transformation

GDP: gross domestic product

HF: high frequency

ICS: intercostal space

ICSD-3: International Classification of Sleep Disorders

LAAS-CNRS: Laboratory for Analysis and Architecture of Systems-French National Centre for Scientific

Research

LD: linear discriminant

LDA: linear discriminant analysis

LF: low frequency

NC: network controller

NREM: nonrapid eye movement

OSA: obstructive sleep apnea

PLMS: periodic limb movement during sleep

PPI: pulse to pulse interval

PSG: polysomnography

RBD: REM sleep behavior disorder

REM: rapid eye movement

RF: random forest

RLS: restless legs syndrome

SAX: symbolic aggregate approximation

SOM: self-organized map

SVM: support vector machine

SWS: slow wave sleep

VLF: very low frequency

WBAN: wireless body area network

W-band: wearable bands

WLBAN: wireless local body area network

WSN: wireless sensor network 
Edited by G Eysenbach; submitted 01.06.20; peer-reviewed by LA Lee, E Kutafina; comments to author 25.06.20; revised version received 05.07.20; accepted 22.07.20; published 26.08.20

Please cite as:

Pan Q, Brulin D, Campo E

Current Status and Future Challenges of Sleep Monitoring Systems: Systematic Review

JMIR Biomed Eng 2020;5(1):e20921

URL: http://biomedeng.jmir.org/2020/1/e20921/

doi: 10.2196/20921

PMID:

(CQiang Pan, Damien Brulin, Eric Campo. Originally published in JMIR Biomedical Engineering (http://biomedeng.jmir.org), 26.08.2020. This is an open-access article distributed under the terms of the Creative Commons Attribution License (https://creativecommons.org/licenses/by/4.0/), which permits unrestricted use, distribution, and reproduction in any medium, provided the original work, first published in JMIR Biomedical Engineering, is properly cited. The complete bibliographic information, a link to the original publication on http://biomedeng.jmir.org/, as well as this copyright and license information must be included. 